\title{
MRI BASED PHYSIOLOGICAL PARAMETERS ARE BIOMARKERS OF TUMOR AND NON TUMOR TISSUE RESPONSE FOLLOWING RADIATION TO BRAIN METASTASES
}

\author{
by \\ Raphael Y. Jakubovic \\ Bachelor of Science, Ryerson University, 2011 \\ Bachelor of Talmudic Letters, Yeshivas Bais Yisroel, 2006
}

\author{
A thesis \\ presented to Ryerson University \\ in partial fulfillment of the \\ requirements for the degree of \\ Master of Science \\ in the Program of \\ Biomedical Physics
}

Toronto, Ontario, Canada, 2014

(c)Raphael Y. Jakubovic 2014 
I hereby declare that I am the sole author of this thesis. This is a true copy of the thesis, including any required final revisions, as accepted by my examiners.

I authorize Ryerson University to lend this thesis to other institutions or individuals for the purpose of scholarly research.

I further authorize Ryerson University to reproduce this thesis by photocopying or by other means, in total or in part, at the request of other institutions or individuals for the purpose of scholarly research.

I understand that my thesis may be made electronically available to the public. 
MRI based physiological parameters are biomarkers of tumor and non tumor tissue response following radiation to brain metastases

$$
\begin{aligned}
& \text { Master of Science } 2014 \\
& \text { Raphael Y. Jakubovic } \\
& \text { Biomedical Physics } \\
& \text { Ryerson University }
\end{aligned}
$$

\begin{abstract}
We sought to determine the utility of early relative blood volume (rCBV), relative blood flow $(\mathrm{rCBF})$ and permeability $\left(\mathrm{K}^{2}\right.$ trans $)$ measurements as biomarkers of radiation response or progression for brain metastases and to characterize early normal tissue changes following stereotactic radiosurgery. Patients were imaged with dynamic susceptibility and dynamic contrast enhanced magnetic resonance imaging at baseline, 1 week and 1 month post-treatment. Tumors outcomes were stratified using volumetric data obtained from structural images. $\mathrm{K}_{\text {trans }}^{2}$ at 1 week and $\mathrm{rCBV}$ at 1 month were identified as predictors of tumor response and progressive disease respectively. Pre-treatment localized dose planning CT images with overlaid isodose distributions outside the tumor were evaluated within all tissue, and segmented gray and white matter. rCBV and rCBF ratio differences between baseline, 1 week and 1 month were compared. Subsequent analysis identified increases in $\mathrm{rCBF}$ and $\mathrm{rCBV}$ ratios occurring in a dose, tissue, and time specific manner.
\end{abstract}




\section{Acknowledgements}

I would like to thank my supervisors, Dr. Richard Aviv and Dr. Ana Pejović-Milić, for their support and guidance. Over the last four years Dr. Aviv has acted as a supervisor and mentor, playing a major role in my academic and research development. I consider my the evolution of my research abilities to be directly attributed to Dr. Aviv. I have also had the distinct pleasure of interacting with Dr.Pejović-Milić throughout my academic career both as an undergraduate and graduate student. Dr.Pejović-Milić has a passion for physics and has always offered insightful advice. I consider myself privileged to be mentored by these individuals and look forward to working with them in the future.

I would also like to thank Dr. Emily Heath for serving as a member of my advisory committee. Dr. Heath's advice an input were much appreciated.

I would like to thank Dr. Arjun Sahgal, Dr. Hany Soliman, and Dr. Mark Ruschin for their contributions to this project and for bringing their unique expertise to the table. Special thanks to Dr. Sahgal for driving this project from the clinical side.

I would also like to acknowledge the MRI technicians and support staff Sunnybrook Health Sciences Centre and the Odette Cancer Centre.

Finally, I would like to acknowledge and thank my peers in both the Aviv and PejovićMilić labs for your support and help over the last few years. Armin Eilaghi, Phillip Frances, Thien Hyunh, and Roger Lui in the Aviv Lab and Eric Da'silva, Brian Kirkham, and Bizma Rizvi, in Pejović-Milić lab. I will always value these experiences. 


\section{Dedication}

This thesis is dedicated to family and friends who have supported me throughout this journey.

To my parents who believed in my abilities before I had the confidence to fulfill them and their continued support and guidance. I would not be here without you.

To Abba \& Eema for forever being a source of inspiration.

To my siblings, Marcel, Eli, and Abi, who have each achieved in their own right, for your words of encouragement.

To my daughter Tamar who makes it all worth it. I hope that you will have the opportunity I've had to follow your dreams.

And finally,

To my wife Pnina

"A happy man is too satisfied with the present to dwell too much on the future." (Albert Einstein, 1896)

The life of the wife of a perpetual student is filled with challenges. You have supported me each step of the way and for that I am truly grateful. May we continue to experience the happiness of the present for the rest of our lives. 


\section{Contents}

\begin{tabular}{lll}
\hline & Introduction & 1
\end{tabular}

1.1 Thesis Organization $\ldots \ldots \ldots \ldots \ldots \ldots \ldots$

1.2 Metastatic Brain Cancer . . . . . . . . . . . . . . . . . . . . . . 1

1.2 .1 Incidence . . . . . . . . . . . . . . . . . . . . . . . . 1

$1.2 .2 \quad$ Clinical Presentation, Quality of Life, and Prognosis . . . . . . . . . . . 2

1.2 .3 Diagnosis . . . . . . . . . . . . . . . . . . . . . 3

1.2 .4 Treatment . . . . . . . . . . . . . . . . . . . . 3

1.3 Tumor Vasculature $\ldots \ldots \ldots \ldots$. . . . . . . . . . . . . . . . . . . 6

1.3 .1 Metastatic Dissemination . . . . . . . . . . . . . 6

1.3 .2 Angiogenesis . . . . . . . . . . . . . . . 6

1.3 .3 Radiation and Metastases . . . . . . . . . . . . . . . . . . . . 7

1.3 .4 Radiation Induced Metastases . . . . . . . . . . . . . . . . . . 7

1.3.5 Radiation Damage and Tumor Regrowth $\ldots \ldots \ldots$. . . . . . . 7

1.3 .6 Normal Tissue Vascular Response . . . . . . . . . . . . . . . . 8

1.4 Functional MRI . . . . . . . . . . . . . . . . . . . . . . . 9

1.4.1 Basic Principles of Dynamic Susceptibility Contrast (DSC) MRI . . . . . 9

$1.4 .2 \quad$ Basic Principles of Dynamic Contrast Enhanced (DCE) MRI . . . . . . . 10

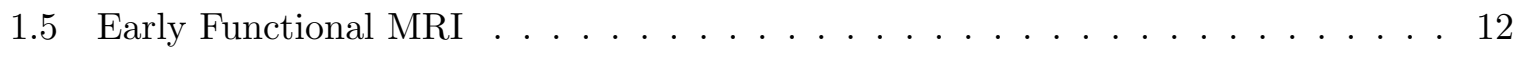

1.5 .1 Tumor Response . . . . . . . . . . . . . . . . . . . 12

1.5 .2 Normal Tissue Response . . . . . . . . . . . . . . . . . . . . 14

1.6 Objective and Specific Aims . . . . . . . . . . . . . . . . . . . . . . . 15

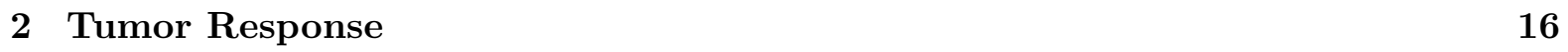

2.1 Abstract . . . . . . . . . . . . . . . . . . . . . . . 17

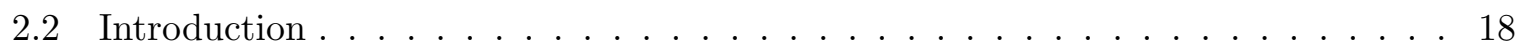

2.3 Methods . . . . . . . . . . . . . . . . . . . . . . . . 19

2.3 .1 Study Design and Patient Cohort . . . . . . . . . . . . . . . . . 19 
2.3 .2 Radiation Treatment . . . . . . . . . . . . . . . . . . . . . 20

2.3 .3 Imaging Acquisition $\ldots \ldots \ldots \ldots \ldots \ldots \ldots$

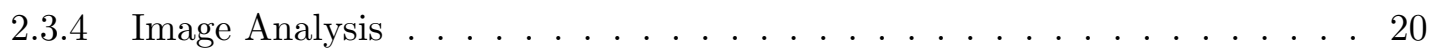

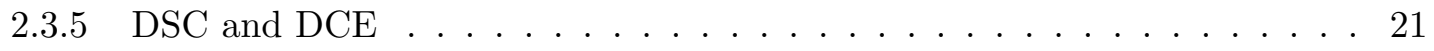

2.3 .6 Statistical Analysis $\ldots \ldots \ldots \ldots \ldots \ldots \ldots$

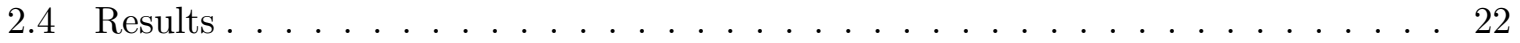

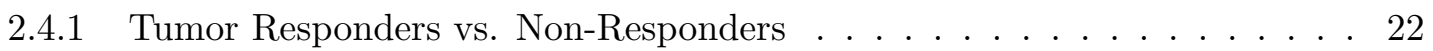

2.4 .2 Progressors vs. Non-Progressors $\ldots \ldots \ldots \ldots \ldots \ldots$

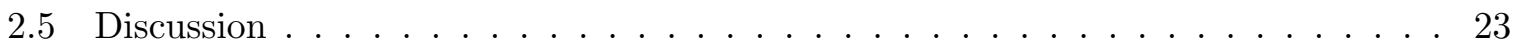

\begin{tabular}{|llr|}
\hline 3 & Normal Brain Tissue Response & 32
\end{tabular}

3.1 Abstract . . . . . . . . . . . . . . . . . . . . . . 33

3.2 Introduction . . . . . . . . . . . . . . . . . . . . . . . . 34

3.3 Methods . . . . . . . . . . . . . . . . . . . . . . . . . 35

$3.3 .1 \quad$ Study Design and Patient Cohort. . . . . . . . . . . . . . . . . . . . 35

3.3 .2 Imaging Acquisition $\ldots \ldots \ldots \ldots \ldots \ldots \ldots$

3.3 .3 Radiation Treatment . . . . . . . . . . . . . . . . . . . . . . . 35

3.3 .4 Image Analysis $\ldots \ldots \ldots \ldots \ldots \ldots$

3.3 .5 Statistical Analysis $\ldots \ldots \ldots \ldots \ldots \ldots \ldots$

3.4 Results . . . . . . . . . . . . . . . . . . . . . . . . 37

3.5 Discussion $\ldots \ldots \ldots \ldots \ldots \ldots \ldots$

$\begin{array}{llr}4 \text { Discussion } & 46\end{array}$

4.1 Discussion and Conclusions . . . . . . . . . . . . . . . . . . 46

4.2 Limitations . . . . . . . . . . . . . . . . . . . . . . . . . . . . . 48

4.3 Future Work $\ldots \ldots \ldots \ldots \ldots$

\begin{tabular}{lc}
\hline Bibliography & 63
\end{tabular} 


\section{List of Tables}

2.1 Baseline clinical variables and compliance for the entire cohort . . . . . . . . . 28

2.2 Mean ROI $\mathrm{K}_{\text {trans }}^{2} \mathrm{rCBF}$ and $\mathrm{rCBV}$ values prior to, 1 week and 1 month following radiation. Comparison of PD vs. non-PD (CR, PR, SD) and tumor response $(\mathrm{CR}, \mathrm{PR})$ vs. non-response $(\mathrm{PD}, \mathrm{SD}) \ldots \ldots \ldots \ldots \ldots$

2.3 Univariate analysis for PD vs. non-PD (CR, PR, SD) and tumor response (CR, $\mathrm{PR})$ vs. non-response $(\mathrm{PD}, \mathrm{SD}) \ldots \ldots \ldots$. . . . . . . . . . . . 30

2.4 Multivariate logistic regression distinguishing responders (CR, PR) from nonresponders (PD, SD) using $\mathrm{K}_{\text {trans }}^{2}$ tumor permeability and distinguishing $\mathrm{PD}$ from non-PD (SD, PR, CR) using rCBV. . . . . . . . . . . . . 31

$3.1 \quad$ Baseline clinical variables $(\mathrm{n}=19$ patients, 22 indexed tumors $)$. . . . . . . . . 38

3.2 Percent of irradiated intracranial volume for each dose level calculated using

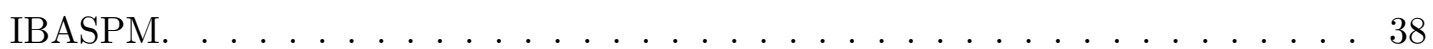

3.3 Mean and standard deviation rCBV and $\mathrm{rCBF}$ ratio values at 1 week and 1 month following radiation for combined, GM, and WM ROIs segmented by dose. 44 


\section{List of Figures}

1.1 Schematic diagram of a Cobalt-60 Gamma Knife radiosurgery unit. . . . . . . . . 5

1.2 Dynamic Susceptibility Perfusion MRI . . . . . . . . . . . . . . . . . . . 10

1.3 Singular Value Decompostion derived CBV and CBF maps . . . . . . . . . . . . 11

1.4 Dynamic Contrast Enhanced MRI . . . . . . . . . . . . . . . . . . . . . 12

1.5 Johnson model derivation of $\mathrm{fBV}$ and $\mathrm{K}^{2}$ trans using in-house interactive data language software. . . . . . . . . . . . . . . . . . . 13

2.1 MR Perfusion and Permeability following treatment with SRS demonstrating progressive disease $\ldots \ldots \ldots \ldots \ldots \ldots . \ldots \ldots \ldots$

2.2 MR Perfusion and Permeability following treatment with SRS demonstrating treatment response . . . . . . . . . . . . . . . . . . 25

3.1 CBV with overlaid dose distribution . . . . . . . . . . . . . . . . . . . 42

3.2 Mean and standard error rCBV and rCBF ratio for combined, GM and WM ROIs at 1 week and 1 month $\ldots \ldots \ldots \ldots$. . . . . . . . . . . 43

3.3 Line of best fit for combined rCBV and rCBF ratio . . . . . . . . . . . . . 45 


\section{Chapter 1}

\section{Introduction and Background}

\subsection{Thesis Organization}

The objective of this thesis is to study early biological changes following radiotherapy in patients with brain metastases. Chapter 1 provides background information regarding diagnosis and treatment of brain metastases, the vascular characteristics of metastatic lesions and normal brain tissue, DSC and DCE MRI imaging, and the importance of early functional imaging following treatment. Chapter 2 presents a study predicting tumor response entitled "MRI-based tumor perfusion parameters are biomarkers predicting response following radiation to brain metastases". Chapter 3 presents normal brain tissue dose response data following radiation entitled "Non tumor perfusion changes following stereotactic radiosurgery to brain metastases". Chapter 4 summarizes and discusses the relevance of these results, presenting limitations and suggestions for future work.

\subsection{Metastatic Brain Cancer}

\subsubsection{Incidence}

The incidence of secondary brain metastasis is estimated to occur in twenty to forty percent of all cancer patients (Posner, 1995; Loeffler et al., 1997). Metastatic disease accounts for approximately $7 \%$ of intracranial tumors and presents in $24 \%$ of all cancer related patient deaths (Posner, 1992; Landis et al., 1998). Incidence of brain metastases in the United States is approximated to be 150,000-200,000 per year, comprising 10-30\% of all patients with cancer and nearly 10 times higher than primary malignancies Gavrilovic 
and Posner, 2005). Recent studies report that 8-10\% of all cancer patients will develop brain metastases (Schouten et al., 2002; Barnholtz-Sloan et al., 2004). Post-mortem autopsy reports reveal that as many as 1 in 3 brain metastases remain undiagnosed and untreated (El Kamar and Posner, 2004). Increased incidence is attributed to an aging population, major advances in the detection of metastases and the successful treatment of many systemic cancers (Lu-Emerson and Eichler, 2012).

\subsubsection{Clinical Presentation, Quality of Life, and Prognosis}

Metastatic brain lesions primarily occur secondary to lung, breast, melanoma, and gastro-intestinal primary tumors (Arnold and Patchell, 2001). Clinical presentation of metastatic disease includes headaches (49\%), focal weakness (30\%), mental/behavioral disturbances $(32 \%)$, gait ataxia $(21 \%)$, seizures $(18 \%)$, speech difficulty $(12 \%)$, visual disturbance $(6 \%)$, and limb ataxia (6\%) (Posner, 1995). Over two-thirds of patients exhibit neurological symptoms over the course of the disease (Posner, 1992). Side effects include acute headaches, nausea, and drowsiness, sub-acute neurological deterioration and late development of necrosis, worsening neurological status and seizures (Tsuruda et al., 1987; Constine et al., 1988). Neurological deterioration is caused by normal tissue damage and/or displacement, vascular damage, peritumoral edema and increased intracranial pressure (Chang et al., 2009; Eichler et al., 2011). Increased intracranial pressure requires immediate treatment to reverse or prevent cerebral herniation and inevitable death $\overline{\text { Pos- }}$ ner, 1992). Since these symptoms severely impact quality of life (QOL) supportive therapy supplements definitive targeted tumor therapy. Supportive therapy plays a major role in improving QOL and includes administration of corticosteroids to reduce edema, anti-depressants to aid the patients ability to cope with the disease, and anti-convulsants to reduce seizure related activity (Lu-Emerson and Eichler, 2012).

The prognosis of patients diagnosed with metastases is poor. Left untreated median survival is approximately 1-2 months (Horton et al., 1971; Markesbery et al., 1978; Langley and Fidler, 2013). Multimodality treatment is successful in extending survival up to 18 months, but often has profound neurological impact (Langley and Fidler, 2011). Prognostic indicators include Karnofsky performance status (KPS), age, presence of extracranial metastatic disease, primary tumor diagnosis, number of brain metastases and time from diagnosis of the primary tumor to the detection of the metastatic lesion (Eichler 
and Loeffler, 2007; Sperduto et al., 2010). KPS evaluates patient functional impairment, is identified a major determinant of survival and is integrated into multiple prognostic scoring systems including Radiation Therapy Oncology Group (RTOG) recursive partitioning analysis (RPA) and score index for radiosurgery (SIR) (Eichler and Loeffler, 2007).

\subsubsection{Diagnosis}

Diagnosis of brain metastases is made using computed tomography (CT) or magnetic resonance imaging (MRI), but the modality of choice is contrast enhanced MRI with or without pathological biopsy confirmation (El Kamar and Posner, 2004). MRI acquisitions involved in diagnosis include unenhanced and enhanced T1, T2, and fluid attenuated inversion recovery (FLAIR) weighted sequences (Essig and Gerigk, 2009). Lesions larger than $1 \mathrm{~cm}$ warrant further investigation and treatment El Kamar and Posner, 2004). Whereas glioma infiltrate the surrounding brain tissues, metastases contain well defined margins that are accurately segmented using contrast - enhanced MRI. The ability to clearly delineate tumor margins makes targeted radiosurgery an attractive treatment option.

\subsubsection{Treatment}

Treatment of brain metastases is complex and dependent on multiple factors including location, number of lesions, primary tumor histology and the scale of systemic disease (Lu-Emerson and Eichler, 2012). According to the 2004 Cancer Care Ontario guidelines brain metastases should be treated with radiation and/or surgery (Tsao et al., 2004). Available treatment options include stereotactic radiosurgery (SRS), whole brain radiotherapy (WBRT), surgery, chemotherapy, and corticosteroids. SRS use circumvents many of the side effects associated with WBRT and results in improved control rates Chang et al., 2009; Sun et al., 2011). Nevertheless, SRS is still associated with increased risk of radiation necrosis increasing with tumor volume (Follwell et al., 2012; Khalsa et al., 2013). 


\section{Stereotactic Radiosurgery (SRS)}

The objective of SRS is to completely destroy a prescribed region, while limiting exposure to surrounding tissues (Maitz and Wu, 1998). It is crucial to deliver a dose that will control the tumor with enough precision to avoid undesired side effects in the surrounding tissues. The technique was pioneered by Lars Leksell with the invention of the Gamma Knife Cobalt-60 radiation unit and was primarily used for well-defined lesions (Leksell, 1983). Alternatively, SRS is delivered using a standard linear accelerator. SRS employs multiple beam geometry to create a conformal beam and deliver a high dose of radiation, ultimately destroying the tumor and delivering sublethal radiation to surrounding normal brain tissue. A schematic of the Gamma Knife setup is shown in Figure 1.1. AAPM guidelines specify that the absorbed dose to the target should contain $<5 \%$ uncertainty and the dose gradient in the beam penumbra (defined by 20-80\% isodose) should be $\geq 60 \% / 3 \mathrm{~mm}$ (Schell et al., 1995). A rapid dose fall-off outside of the target ensures significant sparing of normal brain tissue. Local tumor control can be achieved using SRS in patients with 1-4 lesions and KPS greater than 80 while limiting the neurological decline commonly seen following WBRT. A recent report shows SRS effective in achieving local control in patients with up to 15 metastases (Chang et al., 2010). Local control $>80 \%$ is reported in over 2000 patients treated with SRS (Loeffler et al., 1999). SRS dose plans in our cohort were delivered in concordance with RTOG 9005 guidelines and based on tumor diameter (Shaw et al., 2000).

\section{Whole Brain Radiotherapy (WBRT)}

Whereas the objective of SRS is to completely destroy the target, WBRT employs fractionation and limits normal tissue damage by allowing for tissue repair. This sensitizes the target lesion through re-oxygenation and exploits sensitive phases of the cell cycle (Larson et al., 1993). Typical WBRT dose plans deliver 1.5-4 Gy per fractions daily up to 4 weeks, increasing median survival up to 6 months and reducing the risk of distant recurrence (Arnold and Patchell, 2001; Linskey et al., 2010). Fractionation schemes in our cohort comprised 20 Gy in 5 fractions or 30 Gy in 10 fractions (Tsao et al., 2012). While local control rates remain high retrospective analysis indicates that over $50 \%$ of patients treated with WBRT die as a result of existing systemic diseases as opposed to the actual target lesion (Posner, 1992; Berk, 1995). Patients with more than 4 lesions and KPS $<80$ are treated with WBRT (Khalsa et al., 2013). 


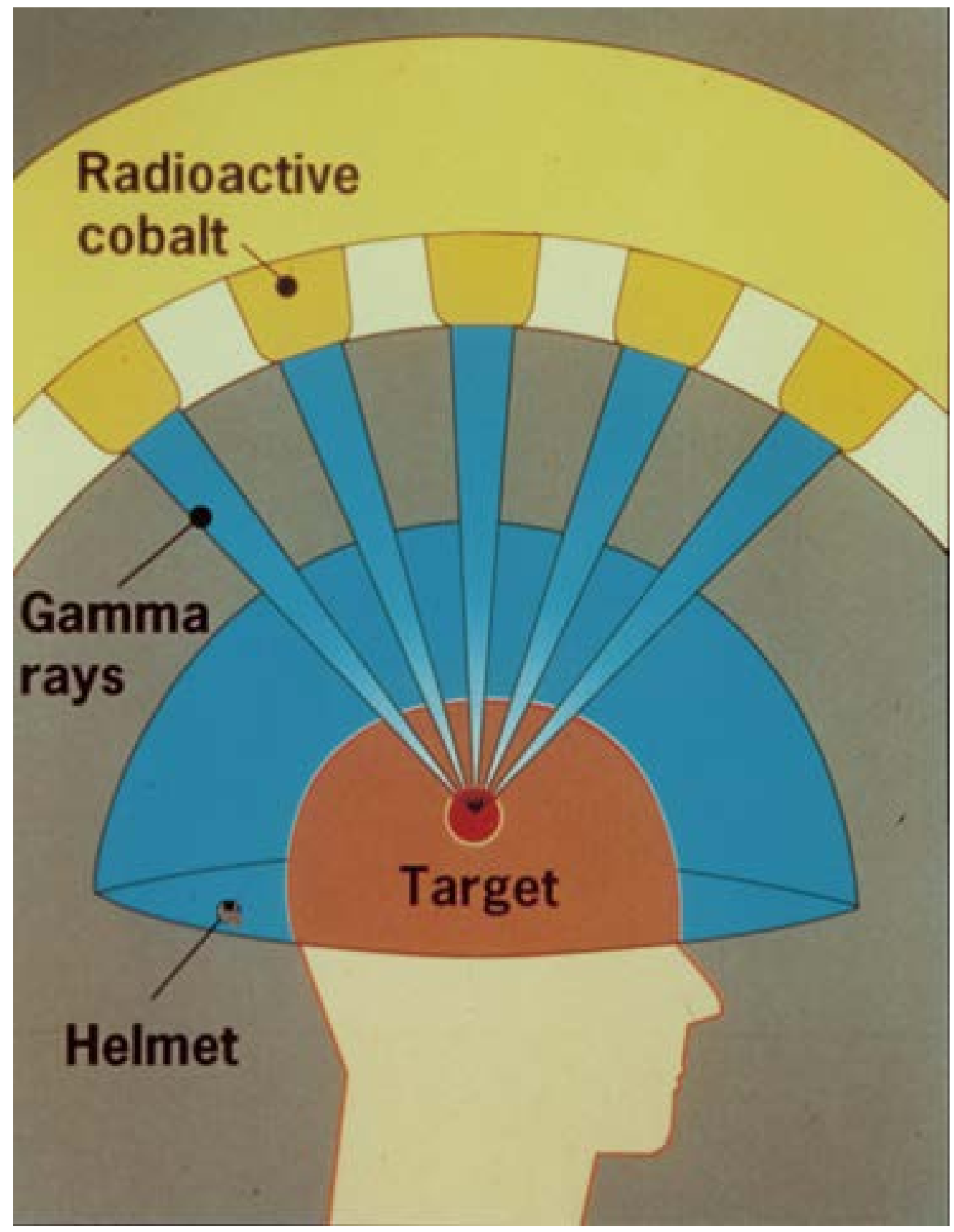

Figure 1.1: Schematic diagram of a Cobalt-60 Gamma Knife radiosurgery unit. Gamma rays are focused on the target area minimizing dose to surrounding tissues.(United States Nuclear Regulatory Commission (NRC), 2007) 


\subsection{Characteristics of Tumor Vasculature}

\subsubsection{Metastatic Dissemination}

The evolution of systemic cancer to metastatic disease comprises a two-step process known as the metastatic cascade whereby the primary cancer cells escape to a secondary site through the vasculature or lymphatic system and survive and proliferate in this new environment (Fidler et al., 1999). The framework by which the metastatic cascade occurs was first investigated in 1889 when Paget proposed the seed and soil hypothesis theorizing that specific tumors (seed) have a special affinity for specific organs (soil) (Paget, 1989). Ewing (1929) believed spread of metastases was purely mechanical and metastatic spread depends solely on the circulatory system. It is now believed that cancer stem cells possess both the seed and soil to migrate to secondary locations and that proliferation depends on the relationship between the tumor cells and secondary tumor site (Langley and Fidler, 2011).

Cerebral circulation is identified as a crucial factor in the dissemination of brain metastases. Tumor cells migrate towards the brain through the arteries and often arrest in areas of narrow blood vessels such as the gray matter (GM) white matter (WM) junction (Delattre et al., 1988; Hwang et al., 1996). Metastatic distribution is also associated with cerebral circulation with the percentage brain lesions corresponding to the relative weight and blood flow found in the cerebral hemispheres (80\%), cerebellum (15\%), and brain stem (5\%) (Delattre et al., 1988; Posner, 1992).

\subsubsection{Angiogenesis}

The ability of the tumor to grow and recover is highly dependent on blood supply and angiogenesis (Hlushchuk et al., 2008). Angiogenesis involves the recruitment of blood vessels and occurs via a sprouting or intussusceptive process. Whereas sprouting angiogenesis creates new vessels from the existing vasculature, intussusceptive angiogenesis involves the co-opting and remodelling of blood vessels (Hlushchuk et al., 2008). Metastasis formation is considered highly inefficient with $<0.01 \%$ of tumor cells actually 
achieving metastatic growth (Fidler et al., 1999).

\subsubsection{Radiation and Metastases}

Radiotherapy has a profound impact on the tumor microenvironment. Local tumor control is achieved by inducing double strand DNA breaks in the tumor cells leading to cell death and apoptosis (Kuonen et al., 2012). While ionizing radiation is effective in arresting tumor development, recent evidence indicates that radiation may also transform the micro-environment contributing to increased invasiveness and risk of metastatic proliferation (Kuonen et al., 2012).

\subsubsection{Radiation Induced Metastases}

Administration of radiation is associated with increased invasiveness and metastatic potential. Increased invasiveness is associated with impaired angiogenesis as induction of hypoxia and/or high levels of vascular endothelial growth factor may stimulate a more agressive phenotype (Pennacchietti et al., 2003; Blouw et al., 2007; Du et al., 2008). Pre-irradiated tumor beds, with decreased microvascular density and increased hypoxia, are more infiltrative than untreated tumor beds (Kuonen et al., 2012). Experimental tumor models also show higher metastatic incidence in tumors with greater hypoxic fractions (Cairns et al., 2001; Rofstad et al., 2005). Similarly, therapeutic induction of hypoxia is implicated in increased invasiveness and necrosis, resulting in a more aggressive metastatic phenotype (Monnier et al., 2008).

\subsubsection{Radiation Damage and Tumor Regrowth}

Vascular attributes specific to brain metastases contribute to prominent radiation damage. Vessel formation following ablative radiotherapy is shown to be a crucial determinant of tumor regrowth, possibly as a result of angiogenesis or through the production of endothelial precursor cells (i.e. vasculogenesis) (Kozin et al., 2012). Rapidly progressing brain metastases are shown to contain enlarged, immature vessels at greater risk of endothelial cell death and/or apoptosis (Kang et al., 2009; Tsai et al., 2005). Proliferation following the administration of radiation is mediated by an angiogenic switch 
whereby irradiated tumor vasculature switches from spouting angiogenesis to intussusceptive angiogenesis (Hlushchuk et al., 2008). A similar initial response with vascular dropout and tumor stasis followed by tumor regrowth is shown in a mouse model of metastatic pancreatic islet cancer and coined evasive resistance (Casanovas et al., 2005; Pàez-Ribes et al., 2009).

Similar results are shown in tumors treated with anti-angiogenic drugs (Pàez-Ribes et al., 2009). Angiogenesis inhibitors and fractionated radiation therapy destroyed immature medullary vascular plexus, leaving cortical vessels intact. Tumor recovery was initiated from preserved vasculature with the number of proliferating tumor cells decreasing from the intact cortical region to the medullary region. This was accompanied by a gradient of varying vessel density from cortical to medullary regions. Tumor regrowth began after about one week followed by a wave of "sprouting (new vasculature)" angiogenesis at four weeks (Pàez-Ribes et al., 2009). This regrowth may stem from inherently aggressive hypoxic tumor cells not affected by anti-angiogenic treatment or irradiation retaining adequate oxygen supply. Alternatively, anti-angiogenic treatment or irradiation may initiate an adaptive response by acting as environmental stressors (Kuonen et al., 2012).

\subsubsection{Normal Tissue Vascular Response}

The physiological response of normal tissue to radiation differs based on whether there is a single shot high dose exposure or multiple sessions delivering a fractionated dose (Wood et al., 2005). Healthy parenchyma does not have the same response to radiation and is considered late reacting relative to fast reacting malignant tumors and metastases (Niranjan et al., 2004). SRS delivers an ablative dose to the tumor, coupled with rapid dose fall-off limiting dose to surrounding tissue, mitigating the extent of normal tissue damage. Conversely, WBRT fractionation schemes deliver a lower dose to all brain tissue, to facilitate therapy of undetected metastatic disease but also allow for normal tissue recovery. This suggests alternate mechanisms of tissue damage. Whereas conventional fractionated therapy targets rapidly dividing cells, radiosurgery is thought to arrest the cell dividing ability (Niranjan et al., 2004). The focal targeted therapy but dose sparing effect to normal tissue of SRS versus the wider coverage of WBRT presents an intriguing clinical dilemma particularly with recent findings of local control following 
SRS in up to 15 brain metastases. (Chang et al., 2010).

\subsection{Functional Magnetic Resonance Imaging}

Technological advances over the past 25 years have established conventional MRI as the gold standard in the diagnosis and follow-up of brain tumors (Covarrubias et al., 2004). Conventional MRI is marked by its ability to provide excellent anatomical demarcation and delineation of tumor margins. However, conventional MRI is limited to morphological observation without physiological information.

Recent focus has shifted towards physiological imaging such as dynamic susceptibility contrast (DSC) imaging. DSC and MR permeability are used to guide stereotactic biopsy, grade glioma, assist in surgery and radiation planning, differentiate between tumor necrosis and recurrence, and predict tumor outcome (Covarrubias et al., 2004).

\subsubsection{Basic Principles of Dynamic Susceptibility Contrast (DSC) MRI}

DSC is the most widely used technique exploiting the change of susceptibility, and hence tissue signal, of a gradient T2 sequence during the passage of a contrast bolus (Jackson et al., 2008). The degree of intensity decrease is assumed proportional to gadolinium tissue concentration (Figure 1.2). Data can be normalized against normal appearing white matter to allow inter- and intra-patient comparison. Using the central volume principle cerebral blood volume $(\mathrm{CBV})$, cerebral blood flow $(\mathrm{CBF})$ and mean transit time (MTT) may be calculated. The central volume principle asserts that MTT $=\mathrm{CBV} / \mathrm{CBF} . \mathrm{CBV}$ is described as the total volume of blood traversing a region in milliliters per $100 \mathrm{~g}$ of tissue. $\mathrm{CBF}$ is described as the volume of blood traversing a region in milliliters per $100 \mathrm{~g}(\mathrm{ml} / 100 \mathrm{~g})$ of tissue per unit time $(\mathrm{ml} / 100 \mathrm{~g} / \mathrm{min})$. MTT is the average time it takes for blood to travel from arterial inflow to venous outflow. CBV and CBF maps may be processed by a number of techniques although typically the data requires deconvolution. In this work perfusion parameters were calculated with positron emission tomography (PET) validated software utilizing singular value decomposition (SVD) (Figure 1.3) (Kudo et al., 2003). When expressed as a ratio relative to normal tissue, perfusion measures are denoted as $\mathrm{rCBV}, \mathrm{rCBF}$, and $\mathrm{rMTT}$. $\mathrm{rCBV}$ is considered 
the most sensitive marker for tumor response reflecting vascular density and correlates with histologic grade (Provenzale et al., 2002).
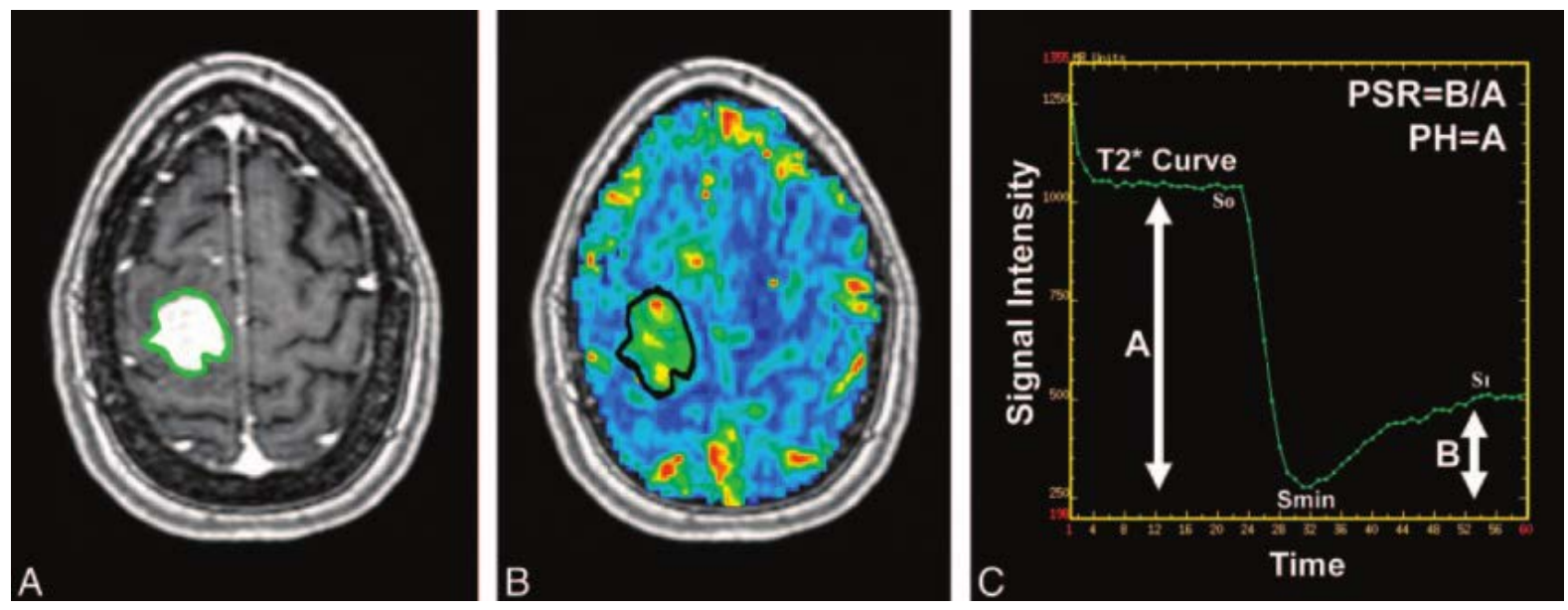

Figure 1.2: A 54 year old woman with a history of recurrent metastatic non-small cell lung cancer 7.7 months after gamma knife radiosurgery. Contrast-enhanced SPGR T1-weighted image (A) and CBV map (B) with a single region of interest surrounding the entire contrastenhancing region demonstrate an enhancing region with corresponding elevated CBV within the right posterior frontal and parietal lobes. (C) Representative $\mathrm{T}^{*}$ signal-intensity time curve obtained from a single region of interest. Peak height $(\mathrm{PH})$ is represented by A (Initial signal intensity $\left(S_{0}\right)$ - Minimum signal intensity $\left(S_{\text {min }}\right)$. Percentage of signal-intensity recovery (PSR) is calculated as B / A $\left(S_{1}-S_{m i n}\right) /\left(S_{0}-S_{m i n}\right)$ (Barajas et al., 2009).

\subsubsection{Basic Principles of Dynamic Contrast Enhanced (DCE) MRI}

Dynamic contrast enhanced MRI is a T1-weighted approach exploiting the change of tissue signal during the passage of a gadolinium bolus. The technique measures leakage of a bolus of contrast through the brain and makes use of an arterial input function. Contrast enhancement is generally considered a marker of tissue vascularity (i.e. fractional blood volume) and contrast accumulation (i.e. microvascular integrity and transendothelial diffusion) (Figure 1.4) (Roberts et al., 2000). This technique is successfully employed to quantify fractional blood volume (fBV) and microvascular permeability (Roberts et al., 2000). Tumor permeability is also associated with histologic grade (Roberts et al., 2001).

$\mathrm{K}_{\text {trans }}^{2}$, considered an estimate of microvascular permeability, is derived from DCE data and is calculated using a two compartment pharmacokinetic model in the present 


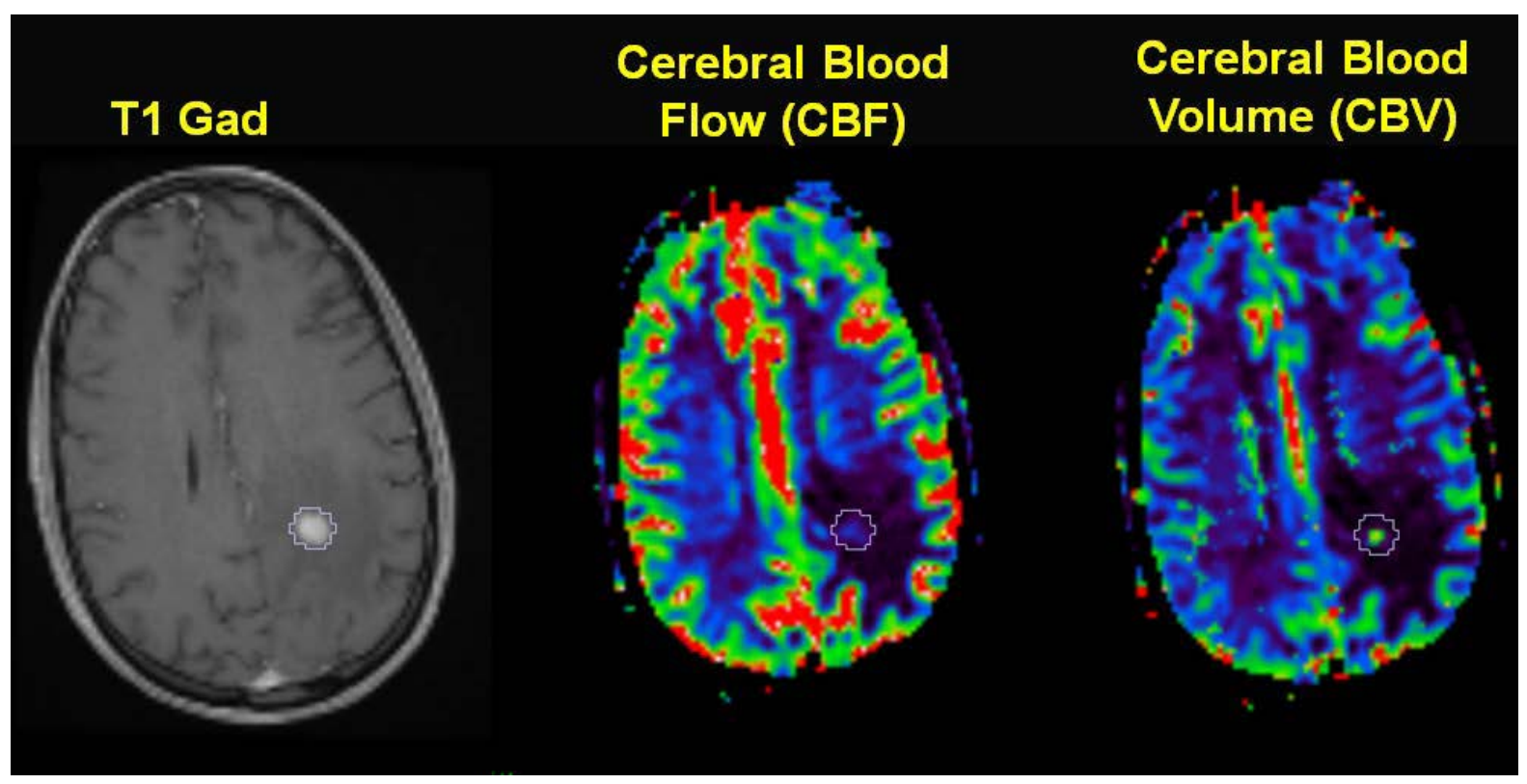

Figure 1.3: DSC CBF and CBV maps calculated using positron emission tomography (PET) validated software utilizing singular value decomposition (SVD). 60 year old female with a history of renal cell carcinoma previously treated with chemotherapy. (A) Post-contrast axial T1-weighted MRI at baseline demonstrates the left parietal lesion treated with $20 \mathrm{~Gy} / 1$ fraction using focal SRS. (B) CBF map at baseline.(C) CBV map at baseline.

work (Johnson et al., 2004; Provenzale et al., 2006). The model accounts for leakage of contrast in the presence of blood brain barrier (BBB) breakdown commonly found in primary and metastatic brain tumors by dividing the data into intra-and extra-vascular components (Cha et al., 2000; Covarrubias et al., 2004). Unlike the Tofts model, the Johnson model allows for diffusion of contrast back into the cerebral circulation. $\mathrm{K}_{\text {trans }}^{2}$ and $\mathrm{fBV}$ are extracted offline with in-house interactive data language (IDL) software as previously published (Figure 1.5) (Kassner et al., 2004). Intra-vascular concentration is considered proportional to $\mathrm{K}^{2}$ trans which is dependent on blood flow, vascular surface area, hydrostatic and osmotic pressure (Law et al., 2004). 

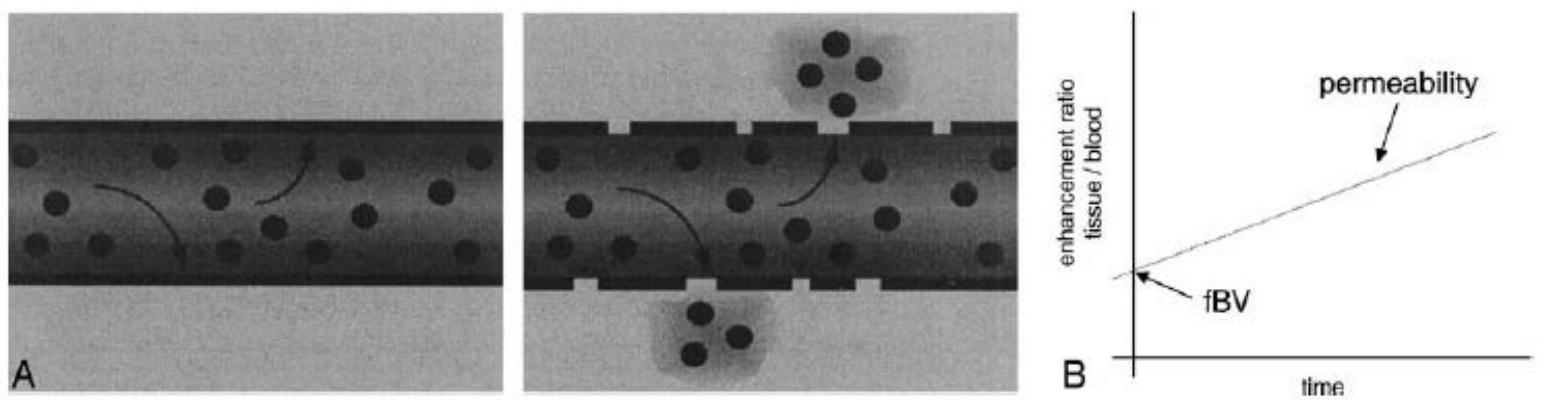

Figure 1.4: (A) Schematic representation of two capillaries containing contrast agent. The healthy capillary with an intact BBB (left) is not permeable to the contrast agent, leading to accumulation of contrast agent outside the vessel (center). (B) Because the contrast agent causes relaxation rate enhancement to water in its environment initial tissue relation rate enhancement reflects the fraction of the tissue containing blood vessels (since the contrast agent is, at least initially confined to the intravascular compartment). The ratio of initial enhancement in tissue to enhancement in a region of $100 \%$ blood (eg, the saggital sinus) will then yield the fBV. Over time, if the contrast agent leaks out of the vessel into the extravascular space of the tissue, the relaxation rate will rise progressively. The rate of increase in relaxation rate is proportional to the permeability of the capillary wall to the contrast agent (Roberts et al., 2000).

\subsection{The Importance of Early Functional Imaging Following Treat- ment}

\subsubsection{Tumor Response}

There is particular interest in the morphological changes occurring in brain tumors following radiotherapy, and several MRI-based studies have demonstrated that changes in lesion size and the extent and pattern of contrast enhancement are predictive of tumor outcome (Therasse et al., 2000). Clinical reports of brain metastases have employed varying response criteria (Follwell et al., 2012). The current gold standard is the response evaluation criteria in solid tumors (RECIST) which defines complete response as a $100 \%$ decrease in in maximum diameter, partial response as a $\geq 30 \%$ decrease in maximum diameter, stable disease as $<30 \%$ decrease and $<20 \%$ increase in in maximum diameter, and progressive disease as $\geq 20 \%$ increase in maximum diameter (Therasse et al., 2000). A recent report proposes and validates a volume specific response criteria based on RECIST (Follwell et al., 2012).

Early tumor response assessment is an important area of research and development 


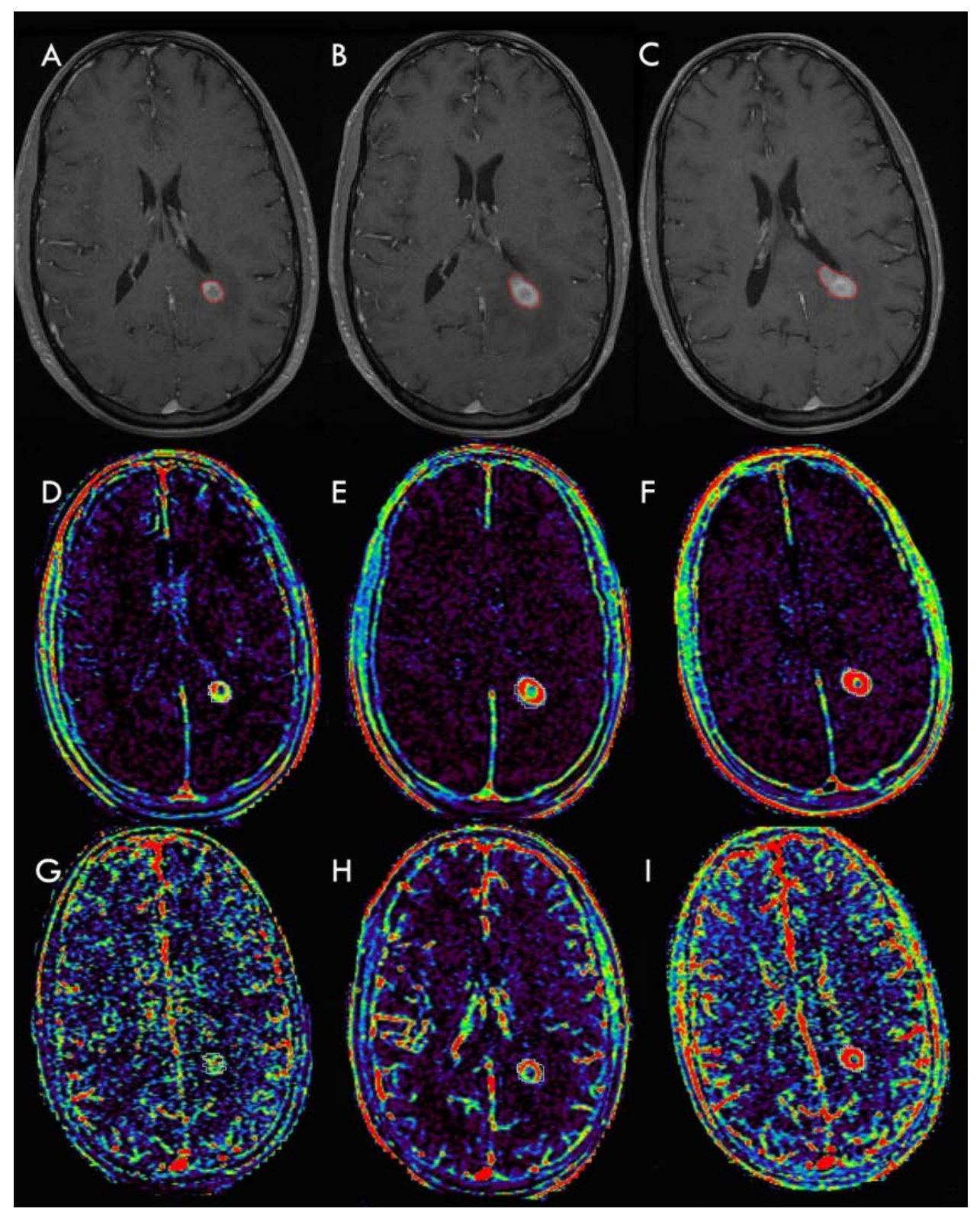

Figure 1.5: Johnson model derivation of $\mathrm{fBV}$ and $\mathrm{K}^{2}$ trans using in-house interactive data language software. 69 year old male with a history of non-small cell lung cancer previously treated with lung irradation and chemotherapy. $(\mathrm{A}-\mathrm{C})$ Serial post-contrast axial T1-weighted MRI demonstrates the left occipital lesion treated with $24 \mathrm{~Gy} / 1$ fraction using focal SRS. Baseline, 1 week, 1 month post contrast T1 images show tumor growth. (D - F) fBV maps at baseline, 1 week, and 1 month. $(\mathrm{G}-\mathrm{I}) \mathrm{K}^{2}$ trans maps at baseline, 1 week, and 1 month. 
as further treatments (i.e. salvage therapy, surgery) may be indicated if a tumor can be identified as resistant and may also increase our ability to discern radiation effect from true tumor progression. Physiological changes following radiotherapy precede any visible structural changes and conventional imaging is only effective 3-6 months post-irradiation (Peterson et al., 1999). Earlier changes are detected using functional imaging and therefore provide an opportunity for earlier assessment of tumor response to treatment Millar et al., 2005).

The phenomena of pseudo-progression, characterized by early increases in tumor volume followed by treatment response, and pseudo-response, characterized by a decrease in tumor volume followed by progression, are well documented in glioma and metastases. DSC and DCE have potential to distinguish very early tumor response prior to structural imaging changes. Specific to metastases, there are reports of DSC based discrimination between progression and response as early as six weeks following radiotherapy and discrimination of recurrence from necrosis after 3 months (Barajas et al., 2009, Essig et al., 2003; Hoefnagels et al., 2009). However, no DCE data for metastatic brain tumor outcome is previously reported. Our study presents both DSC and DCE data at an earlier time point (1 week and 1 month) to determine whether earlier assessment of tumor physiology may be predictive of later outcome.

\subsubsection{Normal Tissue Response}

The normal tissue effect of radiation is well studied. Ionizing radiation is believed to induce single and double strand DNA breaks resulting in inhibition of cell division and promotion of cell death/apoptosis (Oh et al., 2007). The damage occurs rapidly in highly metabolic cancer cells, and may only become apparent over months or years in slowly proliferating tissues (Stone et al., 2003, Oh et al., 2007). Radiation induces vascular damage including vessel dilation, endothelial cell death/apoptosis and microvessel hemorrhage/occlusion (Cao, 2011). The extent of radiation damage depends on total dose, number of fractions (SRS vs. WBRT), dose per fraction, recovery times between fractions, volume of normal tissue receiving high doses of radiation and tissue type (i.e. GM or WM) (Stone et al., 2003).

Early normal tissue response is an important area of research as higher radiation 
doses may be tolerated in tissues identified as radio-resistant. Changes are shown using SPECT, DSC and DCE imaging as early as 6 hours from the start of treatment (Taki et al., 2002; Price et al., 2004, Cao et al., 2009). Conversely, rigorous treatment planning can minimize dose to radiosensitive tissues. Since the effect of radiation on normal brain tissue is not well understood and few studies are reported, a better understanding of the radiobiological effects of radiation in normal brain tissue would be beneficial. The integration of functional MRI into treatment planning would potentially enable assessment of patient-specific tolerances leading to idiosyncratic dose prescription.

\subsection{Objective and Specific Aims}

The objective of this study is to investigate whether early DCE and DSC measurements may serve as MRI biomarkers in brain metastases. The purpose is to determine whether physiological parameters such as, $\mathrm{rCBV}, \mathrm{rCBF}$ and permeability $\left(\mathrm{K}_{\text {trans }}^{2}\right)$ can predict tumor response or progression following radiation and whether vascular change in normal brain tissue can be detected.

Specific Aim 1: Early rCBV, $\mathrm{rCBF}$, and $\mathrm{K}_{\text {trans }}^{2}$ measurements can be used to predict radiation response or progression in brain metastases following SRS and WBRT.

Specific Aim 2: Early rCBV and rCBF changes can be detected in normal tissue occurring in a time, dose and tissue dependent manner. 


\section{Chapter 2}

\section{Tumor Response}

This chapter presents a study predicting tumor response entitled "MRI-based tumor perfusion parameters are biomarkers predicting response following radiation to brain metastases". This work This work comprises a manuscript under review in Clinical Oncology at time of thesis submission.

\section{MRI-based tumor perfusion parameters are biomarkers predicting response following radiation to brain metastases}

Raphael Jakubovic B.Sc. ${ }^{1,2}$, Arjun Sahgal M.D. ${ }^{3}$, Hany Soliman M.D. ${ }^{3}$, Rachael Milwid ${ }^{1}$, Armin Eilaghi Ph.D. ${ }^{3}$ Richard I Aviv MRCP, FRCR, FRCPC ${ }^{1}$

${ }^{1}$ Department of Medical Imaging, Division of Neuroradiology, Sunnybrook Health Sciences Centre, University of Toronto, Toronto, Ontario, Canada

${ }^{2}$ Department of Biomedical Physics, Ryerson University, Toronto, Ontario, Canada

${ }^{3}$ Department of Radiation Oncology, Odette Cancer Centre of the Sunnybrook Health Sciences Centre, University of Toronto, Toronto, Ontario, Canada 


\section{$2.1 \quad$ Abstract}

Purpose: To investigate whether early relative blood volume (rCBV), relative blood flow ( $\mathrm{rCBF}$ ) and permeability $\left(\mathrm{K}_{\text {trans }}^{2}\right)$ measurements may serve as MRI biomarkers of radiation response or progression for brain metastases.

Methods: Seventy brain metastases in 44 patients treated with either stereotactic radiosurgery (SRS) or whole brain radiotherapy (WBRT) were imaged with dynamic susceptibility (DSC) and dynamic contrast enhancement (DCE) MRI at baseline, 1 week and 1 month post treatment. Final response status was determined according to volume criteria derived from a 1 year post-treatment MRI or last available follow-up MRI. Tumors were characterized as responders $(\mathrm{CR}+\mathrm{PR})$, non-responders (PD, SD), progressors $(\mathrm{PD})$ and non-progressors $\left(\mathrm{SD}+\mathrm{PR}+\mathrm{CR}\right.$ ) and compared for $\mathrm{K}_{\text {trans }}^{2}, \mathrm{rCBF}$, and $\mathrm{rCBV}$ differences. Uni - and multi-variate testing evaluated factors associated with tumor response and progression at 1 week and 1 month. Receiver operator characteristic (ROC) analysis identified optimal cut-off values, sensitivity and specificity for response or progression.

Results: Tumor responders demonstrated lower $\mathrm{K}_{\text {trans }}^{2}$ and reduced $\mathrm{rCBF}$ at 1 week $(\mathrm{p}<0.05$ each). PD demonstrated lower $\mathrm{rCBF}$ and reduced $\mathrm{rCBV}$ at 1 month $(\mathrm{p}<$ 0.05 each). Multivariate analysis (MVA) revealed lower $\mathrm{K}_{\text {trans }}^{2}$ at 1 week, absence of prior radiation predicted response. At 1 month only lower rCBV predicted PD on MVA. Optimal cut-off points for $\mathrm{K}^{2}$ trans and $\mathrm{rCBV}$ were 1.37 and 2.03 with sensitivity and specificity of, $61.5 \%$ and $81.1 \%$, and $73.9 \%$ and $81.8 \%$, respectively.

Conclusion: Lower $\mathrm{K}_{\text {trans }}^{2}$ at 1 week and $\mathrm{rCBV}$ at 1 month discriminated responders and PD respectively. 


\section{$2.2 \quad$ Introduction}

Cerebral metastases occur in approximately 20-40\% of all cancer patients (Posner, 1995; Loeffler et al., 1997). The predominant treatment options include stereotactic radiosurgery (SRS) and/or whole brain radiation therapy (WBRT) (Soliman et al., 2010; Sun et al., 2011; Tsao et al., 2012). WBRT is by far the most common therapy for brain metastases, and on its own is effective in reducing the incidence of new brain metastases (Tsao et al., 2012). However, WBRT may not yield optimal local control rates, and the toxicities of WBRT can be significant due to decline in both neurocognitive function and quality of life (Chang et al., 2009; Sun et al., 2011). Alternatively, SRS as a sole treatment modality avoids the adverse effects of WBRT and is effective with respect to local tumor control. However, with SRS, tumor control rates decrease and the risk of radiation necrosis increases with increasing tumor volume (Follwell et al., 2012).

The combination of WBRT and SRS has been investigated in randomized trials and found to optimally control the brain with respect to both the development of new brain metastases and local tumor control (Tsao et al., 2012). Combined treatment increases the risk of radiation necrosis compared to SRS alone, and exposes the patient to the toxicities of WBRT (Patchell et al., 1998; Kocher et al., 2011). Given that there is no survival benefit to the addition of WBRT to SRS, some argue that it is difficult to justify the toxicities of WBRT despite the added benefits (Tsao et al., 2012). Therefore, at this time the selection of patients for combined modality therapy is unclear. Early biomarkers of tumor response may aid in identifying patients, initially treated with either WBRT or SRS, who could benefit from combined modality therapy. Ideally, these biomarkers could characterize response early and identify the need for further therapy within the first weeks following initial treatment.

Our aim was to investigate the predictive capacity of early changes in tumor perfusion and permeability in patients with brain metastases treated with either SRS or WBRT given that current research supports the notion that changes in tumor physiology pre-

cede imaging-based structural changes following radiotherapy (Vlad et al., 2008; Soliman et al., 2010). 


\subsection{Methods}

\subsubsection{Study Design and Patient Cohort}

Forty-four patients with 70 tumors treated with either SRS $(\mathrm{n}=47)$ or WBRT (n $=23$ ) were prospectively enrolled in this phase 2 observational study approved by our local institutional research ethics board (IRB). The study was opened March 2008 and closed April 2011. No a priori sample size was determined as the study was aimed at providing baseline data on which to base a larger planned study for validation. Inclusion criteria were age $\geq 18$, able to provide consent for the MRI protocol, radiographic diagnosis of brain metastases, pathologic confirmation of a solid tumor primary cancer, life expectancy greater than 6 months, a Karnofsky performance status (KPS) greater than 70 and planned therapy either SRS or WBRT. Patients with any contraindication to MRI, prior allergic reactions to MRI contrast agent, or a treatment plan including WBRT and SRS boost were excluded. DSC and DCE MRI were performed at baseline, 1 week and 1 month following treatment. Thereafter, patients were followed with a diagnostic MRI at 2 month intervals until death or inability to comply. Every MRI study included an axial volumetric T1 post-gadolinium to permit volumetric tumor measurements. The biomarkers of interest included $\mathrm{K}^{2}{ }_{\text {trans }}$, cerebral blood volume (CBV), and cerebral blood flow $(\mathrm{CBF}) . \mathrm{K}^{2}$ trans is a measure of permeability derived from DCE MRI that assesses the leakiness of the tumor vasculature as a function of transendothelial transport of contrast Kassner et al., 2004). Based on a two compartment model, $\mathrm{K}_{\text {trans }}^{2}$ quantifies the transfer constant between blood plasma and tumor - a surrogate measure of blood brain barrier integrity (Roberts et al., 2000; Provenzale et al., 2002). CBV and $\mathrm{CBF}$ are calculated from susceptibility changes during passage of contrast through the cerebral tissues with the DSC sequence. CBV reflects the fraction of tissue volume occupied by blood and is considered a sensitive marker for tumor response. CBF reflects the volume of blood traversing a region per unit time (Weber et al., 2006). Both CBF and $\mathrm{CBV}$ are calculated using the central volume principle (Kudo et al., 2003).

Baseline clinical parameters recorded included age, gender, baseline volume (obtained using Medical Image Processing, Analysis and Visualization software: MIPAV; Center for Information Technology, National Institutes of Health, version 4.4.1.), radiation type (SRS vs. WBRT), if prior WBRT had been delivered, radiation dose, steroid dose, recursive partitioning analysis (RPA) score, KPS, Eastern Cooperative Oncology Group (ECOG) performance status and whether extracranial disease status was stable or pro- 
gressing.

\subsubsection{Radiation Treatment}

All patients were treated with either SRS or WBRT. SRS was delivered with a linear accelerator based technique. SRS dose selection was based according to tumor diameter in accordance to RTOG 9005 (Shaw et al., 2000). For those treated with WBRT, treatment with either 30 Gy in 10 fractions or 20 Gy in 5 fractions was delivered using standard lateral parallel-opposed fields. To control for possible confounding effects by steroids on functional MRI parameters (Ostergaard et al., 1999), patient's dexamethasone dose was maintained constant until the 1 week post-treatment MRI was performed. Thereafter, most patients were put on a tapering schedule according to clinical indications. Dexamethasone dose at the time of each MRI was recorded.

\subsubsection{Imaging Acquisition}

All brain sequences were performed on a 1.5 T GE Twinspeed (General Electric, Mississauga, Canada) MRI, and included a diffusion weighted (DWI) image $(7000 \mathrm{~ms} / \mathrm{min}$ [repetition time (TR)/echo time (TE)], field of view [FOV] of $24 \mathrm{~cm}$, matrix $128^{*} 128$, section thickness (ST) of $5 \mathrm{~mm}$ with no gap); a fluid attenuated recovery inversion (FLAIR) image (8000/120/200 TR/TE/inversion time (TI)], FOV $24 \mathrm{~cm}$, matrix 320*224, ST 5, 1 mm gap); a sagittal T1 FLAIR (2200/24/750 [TR/TE/TI], FOV 24 cm, matrix 224*320, number of excitations (NEX) 2, ST $5 \mathrm{~mm}, 1 \mathrm{~mm}$ spacing); a 3D T1 spoiled gradient echo (SPGRE) DCE, (TE Min, flip angle (FA) 30, FOV $24 \mathrm{~cm}$, matrix 256*128, NEX 1 ; and a DSC study $(1700 / 31.5 / 90$, FOV $24 \mathrm{~cm}$; section thickness $5 \mathrm{~mm}$; matrix 128 * 128; no gap). Gadovist $0.1 \mathrm{ml} / \mathrm{kg}, 1 \mathrm{mmol} / \mathrm{l}$ concentration was injected at $5 \mathrm{~mL} / \mathrm{s}$ for each of the DSC and DCE studies. The DSC and DCE studies were followed by a post-gadolinium 3D T1 fast spoiled gradient echo (FSPGRE) (8.5/4.2, FA 20, FOV 22 $\mathrm{cm}$, matrix $270 * 270, \mathrm{NEX} 1)$.

\subsubsection{Image Analysis}

Volume Analysis 
Three-dimensional (3D) volume assessments were performed for all marker lesions at all time-points based on segmentation on the contrast enhanced volumetric T1-post gadolinium images using MIPAV software. Segmented volumes were recorded in a separate database blinded to clinical outcome. The volume-based criteria for tumor response were based on Follwell et al (Follwell et al., 2012). In brief, progressive disease (PD) requires an increase in the $3 \mathrm{D}$-based volume by $\geq 71.5 \%$; stable disease $(\mathrm{SD})$ refers to 3D-based volume changes between an increase of no more than $71.5 \%$ and a decrease of no more than 58.5\%; partial response (PR) requires a decrease in the $3 \mathrm{D}$-based volume by $\geq$ $58.5 \%$ with tumor still visible; and complete response (CR) indicates complete resolution of the tumor (Follwell et al., 2012). The final tumor response was based on meeting the pre-defined volume criteria at any time during follow-up, at the 1 year post-irradiation MRI or at the last follow-up MRI. Patients were also censored at the time of the last MRI prior to any salvage surgery, further radiation treatment or death.

\subsubsection{DSC and DCE}

DSC maps were calculated with positron emission tomography (PET) validated software utilizing singular value decomposition (SVD) (Kudo et al., 2003). DCE data were processed offline with in-house interactive data language (IDL) software as previously published (Kassner et al., 2004). Regions of interest (ROIs) were drawn around the tumors for all time-points on DCE derived permeability maps. Volumetric T1-post gadolinium images with segmented tumor ROIs were co-registered to DSC using a tri-linear interpolation algorithm in statistical parametric mapping 8 (SPM8, Welcome Trust, London, United Kingdom). A contralateral mirror region was reflected to facilitate relative perfusion value calculation.

\subsubsection{Statistical Analysis}

For each tumor and MRI time point, $\mathrm{K}_{\text {trans }}^{2}, \mathrm{CBF}$, and $\mathrm{CBV}$ were extracted from ipsi-and contra-lateral ROIs from the DSC and DCE maps, respectively. Mean comparisons of $\mathrm{K}_{\text {trans }}^{2}$, rCBF and rCBV ROIs at baseline, 1 week, and 1 month for tumor responders $(\mathrm{CR}+\mathrm{PR})$ vs. non-responders $(\mathrm{SD}+\mathrm{PD})$, and tumor progressors $(\mathrm{PD})$ vs. non-progressors $(\mathrm{SD}+\mathrm{PR}+\mathrm{CR})$, were performed using the Mann-Whitney test. 
Univariate analysis of the multiple baseline clinical parameters was performed including age, gender, baseline volume, previous chemotherapy, radiation type (SRS vs. WBRT), previous radiation, radiation dose, steroid dose, recursive partitioning analysis (RPA) class, KPS and ECOG performance status, in addition to rCBV, rCBF, $\mathrm{K}^{2}$ trans. Variables with $\mathrm{p}<0.3$ were subjected to a stepwise multivariate logistic regression. ROC analysis was used to discriminate $\mathrm{rCBF}, \mathrm{rCBV}$ and $\mathrm{K}^{2}$ trans thresholds that distinguished progressors from non-progressors and non-responders from responders. All analyses were performed using SPSS 17.0 with $\mathrm{p}<0.05$ considered significant.

\subsection{Results}

Of 46 patients recruited into the study, 44 patients harboring 70 metastases were analyzed. One patient was excluded due to impaired renal function that prevented follow-up MRI and the other patient withdrew from the study prior to the 1 week follow-up. Baseline tumor and patient characteristics are described in Table 2.1. Forty-four tumors from 34 patients were treated with SRS with doses ranging from 15-24 Gy in a single fraction. Three patients were treated with fractionated SRS with doses of 35 Gy in 5 fractions. The remaining patients were treated with fractionated WBRT with either 20 Gy in 5 fractions or 30 Gy in 10 fractions. Prior to treatment, 26 patients received dexamethasone with a median dose of $4 \mathrm{mg}$ (range, 2-12). Compliance with follow-up MRI is described in Table 2.1, and at 1 year follow-up MRIs were obtained in 29 patients (65.9\%). The median (interquartile range (IQR)) survival was 8.87 (3.04-21.41) months. With respect to local control, 11 tumors (15.7\%) had PD, 30 (42.8\%) had SD and 29 (41.4\%) had a response (24 PR, $5 \mathrm{CR}$ ). The 1 year local control rate was $84.3 \%$. $\mathrm{K}^{2}$ trans, $\mathrm{rCBF}$, and rCBV values at baseline, 1 week and 1 month for $\mathrm{PD}$, non-PD, tumor response (CR, $\mathrm{PR}$ ) and non-response (PD, SD) are provided in Table 2.2. There were no significant differences in the contra-lateral normal tissue regions at all time-points for all measures (Table 2.3).

\subsubsection{Tumor Responders $(\mathrm{PR}+\mathrm{CR})$ vs. Non-Responders $(\mathrm{PD}+\mathrm{SD})$}

Lower $\mathrm{K}_{\text {trans }}^{2}$ and reduced $\mathrm{rCBF}$ significantly discriminated tumor responders $(\mathrm{CR}$, $\mathrm{PR}$ ) from non-responders $(\mathrm{PD}, \mathrm{SD})$ at 1 week $\left(\mathrm{K}^{2}{ }_{\text {trans }}: 1.67 \pm 1.16\right.$ vs. $2.52 \pm 1.14$; 
$\mathrm{P}=0.003, \mathrm{rCBF}: 2.06 \pm 2.96$ vs. $1.09 \pm 0.88 ; \mathrm{P}=0.041$ ) (Table 2.2). At 1 month a trend towards lower $\mathrm{K}^{2}$ trans was seen in tumor responders relative to non-responders $(\mathrm{P}=0.063)$. Univariate analysis also identified absence of prior radiation therapy as a significant predictor of tumor response $(\mathrm{P}<0.001)$ (Table 2.3). ROC analysis identified the optimal $\mathrm{K}_{\text {trans }}^{2}$ threshold at 1 week as 1.37 with sensitivity, specificity and AUC of $61.5 \%, 81.1 \%$ 71.7\%., respectively. Seven (18.9\%) non-responding tumors had $\mathrm{K}_{\text {trans }}^{2}$ less than 1.37. Neither $\mathrm{K}_{\text {trans }}^{2}, \mathrm{rCBF}$, or $\mathrm{rCBV}$ were able to discriminate between tumor responders and non-responders at 1 month. Following multivariate logistic regression analysis (Table 2.4), lower $\mathrm{K}_{\text {trans }}$ in responders at 1 week $(\mathrm{P}=0.026$; $\mathrm{OR}=1.9195 \%$ CI $[1.08,3.36])$, absence of prior radiation $(\mathrm{P}=0.001 ; \mathrm{OR}=0.129 ; 95 \% \mathrm{CI}[0.039,0.405])$ remained significant predictors of tumor response.

\subsubsection{Progressors (PD) vs. Non-Progressors (non-PD)}

$\mathrm{K}_{\text {trans }}^{2}, \mathrm{rCBV}$ and $\mathrm{rCBF}$ did not discriminate between $\mathrm{PD}$ and non-PD at 1 week. $\mathrm{rCBF}$ and $\mathrm{rCBV}$ values were significantly lower in patients with $\mathrm{PD}$ vs. non-PD at 1 month (rCBF: $2.47 \pm 1.90$ vs. $3.41 \pm 1.48$; $\mathrm{P}=0.048$; rCBV: $2.23 \pm 1.68$ vs. $3.78 \pm$ $1.70 ; \mathrm{P}=0.008)$ on univariate analysis. Prior radiation was a significant predictor for PD (Table 2.3). ROC analysis identified thresholds of 2.03 and 3.08 for $\mathrm{rCBF}$ and $\mathrm{rCBV}$, respectively. The sensitivity, specificity and AUC for $\mathrm{rCBF}$ and $\mathrm{rCBV}$ were $82.2 \%, 66.7 \%$ and $70.9 \%$, and $73.9 \%, 81.8 \%$ and $77.0 \%$, respectively. Two progressive disease tumors had rCBV values greater than 3.08. Four (36.4\%) progressive disease tumors (including the two PD that had $\mathrm{rCBV}$ greater than the threshold) had $\mathrm{rCBF}$ values greater than 2.03. Following logistic regression analysis (Table 2.4 ) only a lower rCBV at 1 month (P $=0.008 ; \mathrm{OR}=0.444 ; 95 \% \mathrm{CI}[0.243,0.812])$ remained a significant predictor of PD.

\subsection{Discussion}

We report the only analysis of DCE MRI and the largest analysis using DSC MRI specific to brain metastases following radiation, with the aim of evaluating potential early biomarkers of tumor response. Our intensive perfusion MRI protocol consisted of DSC and DCE MRI at baseline, 1 week and 1 month following treatment, followed by structural MRIs at 2 month intervals. The results from our study suggest that early $\mathrm{K}^{2}$ trans 


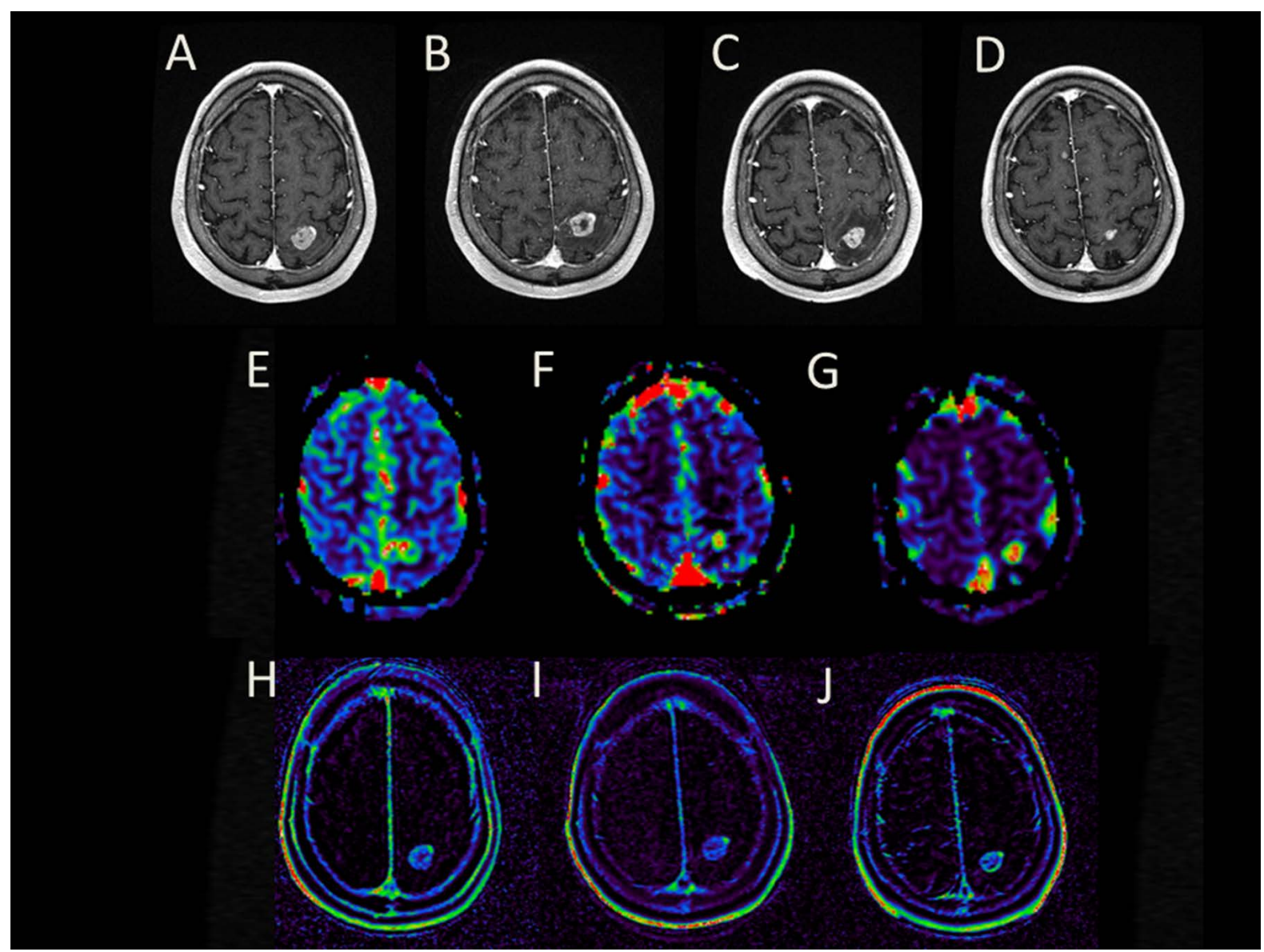

Figure 2.1: PR in a 49 year old male with a history of non-small cell lung cancer presenting with right sided numbness. (A - D) Serial post-contrast axial T1-weighted MRI demonstrates the left parietal lesion treated with $20 \mathrm{~Gy} / 1$ fraction using focal SRS. Baseline, 1 week, 1 month and 6 months post contrast T1 image shows transient enlargement of the parietal metastatic lesion ( 1 week, 1 month) followed by significant reduction in tumor size at 6 months. $(\mathrm{E}-\mathrm{G})$ CBV at baseline, 1 week, and 1 month. Mean ROI rCBV was 8.29 at 1 month. $(\mathrm{H}-\mathrm{J}) \mathrm{K}^{2}$ trans maps at baseline, 1 week, 1 month. Mean ROI $\mathrm{K}^{2}$ trans at 1 week was 0.22 .

reduction relative to non-responders, can predict radio-responsiveness, whereas a lower rCBV at 1 month distinguished disease progression from non-progression.

Despite known variability of permeability change in gliomblastoma post-treatment, post-radiation changes in metastases are largely unknown. Lower $\mathrm{K}^{2}$ trans in responders relative to non-responders was the only imaging marker predictive of response on multivariate analysis. Radiation increases tumor vascular endothelial apoptosis and perfusion 


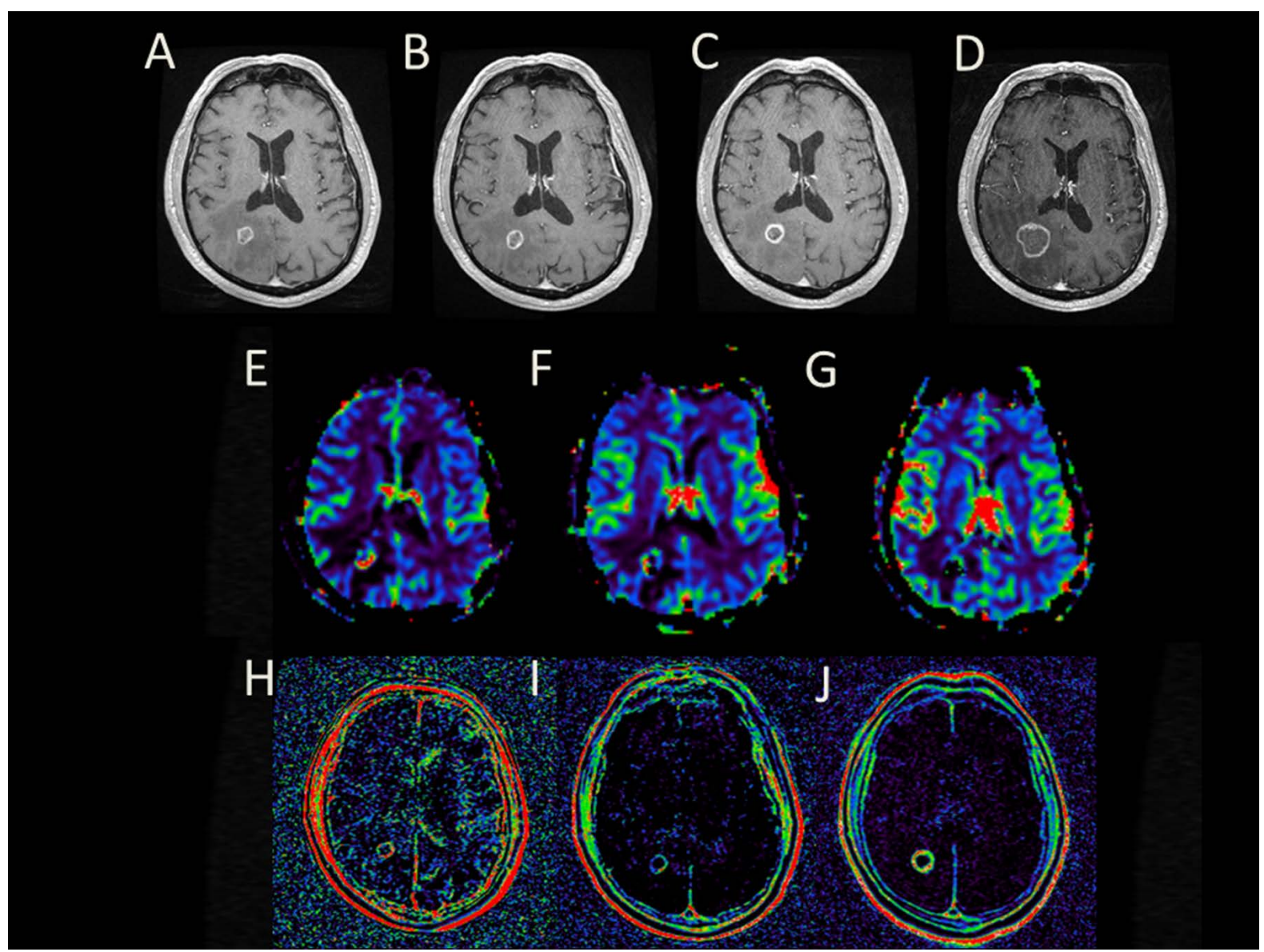

Figure 2.2: $\mathrm{PD}$ in a 62 year old male with a history of renal cell carcinoma, no neurological deficits and Karnofsky Performance Status of 80. (A - D) Serial post-contrast axial T1weighted MRI demonstrating a single right parietal brain metastasis treated with $21 \mathrm{~Gy} / 1$ fraction using focal SRS. Baseline, 1 week, 1 month and 1 year post-contrast T1 MRI shows enlargement of the metastatic lesion. Continued enlargement was seen for up to 13 months post-SRS before surgery was performed (images not shown). (E-G) CBV maps at baseline, 1 week, and 1 month. Mean ROI rCBV at 1 month was 2.84. $(\mathrm{H}-\mathrm{J}) \mathrm{K}^{2}$ trans maps at baseline, 1 week, 1 month. Mean ROI $\mathrm{K}^{2}$ trans at 1 week was 1.86 .

within the first week of treatment (Folkman and Camphausen, 2001), however by 1 week post therapy this effect is counteracted by the decrease in angiogenic signaling secondary to tumor cell kill. These factors ultimately inhibit permeability and may result in a relatively stable $\mathrm{K}_{\text {trans }}^{2}$ relative to baseline in responders Nordal and Wong, 2005; Lu et al., 2012). This finding is consistent with a prior study of glioblastoma demonstrating an early increase in permeability following WBRT with a return to baseline five days after 
the completion of treatment (Millar et al., 2005). Conversely a recent study demonstrates an increase in permeability at 3 and 7 days following SRS in mice correlates with tumor growth, and therefore tumor progression (Chung et al., 2013). Low $\mathrm{K}^{2}$ trans in responders relative to non-responders may reflect early inhibition of angiogenesis whereby radiation induces a localized anti-angiogenic micro-environment increasing the potential for eventual response (Kargiotis et al., 2010).

Although tumor type and treatment regimen were not significant predictors of response we did observe absence of prior radiation predicted tumor response. There is evidence to suggest that prior radiation therapy modifies the tumor micro-environment potentially contributing to increased local invasion and metastatic potential Kuonen et al., 2012).

Essig previously reported that an early increase in rCBV at 6 weeks differentiated PD from non-PD with a sensitivity, specificity and positive predictive value of $91 \%, 71 \%$, and $83 \%$ respectively (Essig et al., 2003). In the present study a reduction in rCBV at 1 month characterized PD. The apparent discrepancy between that study and ours is likely explained by the different time at which rCBV was measured. Indeed, vascular changes post-radiation treatment have been demonstrated to be highly time dependent through the "angiogenic switch mechanism" occurring in tumor vasculature in response to environmental stress such as radiation therapy (Hlushchuk et al., 2008). This switch results in a shift in vascular formation from sprouting to radiation-induced intussusceptive angiogenesis (Hlushchuk et al., 2011).

Intussusceptive angiogenesis involves capillary growth through transcapillary pillar insertion. The process has been observed from 6 days post treatment up to 1 month. During this period there is progressive but transient normalization of the tumor vasculature due to pruning of ineffective leaky vessels, associated with an rCBV drop of up to $40 \%$ (Burri et al., 2004; Hlushchuk et al., 2008). Prior to this an increased vascular permeability and significantly increased blood volume observed in the first week may be attributed to vascular endothelial damage before any substantial intussusceptive response has occurred. Beyond 1 month a second wave of sprouting angiogenesis accompanied by a rising rCBV may then occur as described by Essig (Jain et al., 2007). These processes highlight the complex and sometimes discordant relationship between tumor permeability and vascularity previously described in the primary brain tumor literature 
(Cha et al., 2003; Law et al., 2004; Bulakbasi et al., 2005). The discrepancy is potentially further compounded in metastatic disease by the lack of BBB within secondary tumoral vasculature (Long, 1979; Deeken and Löscher, 2007, Cha, 2009).

With respect to the initial clinical dilemma of patient selection for combined modality therapy following initial treatment with SRS or WBRT, these data may facilitate tumor-specific decision making. Tumors with increased $\mathrm{K}_{\text {trans }}^{2}$ at 1 week or decreased rCBV at 1 month may be considered for combined therapy given the higher likelihood of subsequent tumor non-response or progression respectively. Conversely, tumors with no change in $\mathrm{K}_{\text {trans }}^{2}$ at 1 week or rCBV at 1 month may be candidates for sole modality therapy to avoid the risks of combined therapy. Our findings do, however require validation in a larger sample size, currently underway at our institution.

Limitations of this study include the heterogeneity of tumor types, different treatment regimens, and the lack of control for dexamethasone dose beyond the 1 week scan. Although the patient cohort studied represents the largest studied to date, the number of metastases available for subgroup analysis remains a limitation. Lastly, we limited the time at which response was determined to the 1 year follow-up although long-term survivors may have tumors that ultimately progress. This approach is reasonable given that most patients die within a year following diagnosis.

In conclusion we observed a lower $\mathrm{K}_{\text {trans }}^{2}$ in responders relative to non-responders at 1 week post-irradiation as predictive of tumor response. Progressive disease demonstrated a low rCBV at 1-month relative to non-progression. Further study is required to determine whether these biomarkers can serve as clinically useful surrogates to guide treatment decisions. 
Table 2.1: Baseline clinical variables and compliance for the entire cohort $(\mathrm{n}=44$ patients, 70 index metastases)

\section{Clinical Variable}

\begin{tabular}{|c|c|}
\hline Age (yrs) Median (IQR) & $58.0(48.5-66.0)$ \\
\hline Male Gender & $14(32 \%)$ \\
\hline \multicolumn{2}{|l|}{ Primary Tumor Diagnosis: } \\
\hline Breast & $17(38.6 \%)$ \\
\hline Lung & $12(27.3 \%)$ \\
\hline Melanoma & $7(15.9 \%)$ \\
\hline Renal Cell & $5(11.4 \%)$ \\
\hline Uterine & $2(4.5 \%)$ \\
\hline Germ Cell & $1(2.3 \%)$ \\
\hline Baseline Volume (range) $\left(\mathrm{cm}^{3}\right)$ & $1.815(0.033-12.129)$ \\
\hline \multicolumn{2}{|l|}{ Radiation Treatment: Patients (Tumors) } \\
\hline Stereotactic Radiosurgery & $34(44)$ \\
\hline Fractionated SRS & $3(3)$ \\
\hline Whole Brain Radiotherapy & $7(23)$ \\
\hline Previous Radiation & $24(54.5 \%)$ \\
\hline Previous Chemotherapy & $34(77.3 \%)$ \\
\hline \multicolumn{2}{|c|}{ Recursive Partitioning Analysis (RPA) Class: Patients } \\
\hline 1 & 16 \\
\hline 2 & 2 \\
\hline 3 & 26 \\
\hline Median SRS Radiation Dose (Range) (Gy) & $20(15-35)$ \\
\hline \multicolumn{2}{|l|}{ WBRT Dose: } \\
\hline 20 Gy in 5 fractions & 3 \\
\hline 30 Gy in 10 fractions & 4 \\
\hline \multicolumn{2}{|l|}{ Baseline Karnofsky Performance Status } \\
\hline Median (IQR) & $80(70-90)$ \\
\hline \multicolumn{2}{|l|}{ Baseline ECOG: } \\
\hline 1 & 3 \\
\hline 2 & 37 \\
\hline 3 & 3 \\
\hline 4 & 1 \\
\hline Baseline Steroids & $26(59.1 \%)$ \\
\hline \multicolumn{2}{|l|}{ Number of MRI (\% Compliance): } \\
\hline Baseline & $44(95.6)$ \\
\hline 1 week & $44(95.6)$ \\
\hline 1 month & $41(89.1)$ \\
\hline 3 months & $32(69.6)$ \\
\hline 6 months & $21(45.6)$ \\
\hline 1 year & $29(63.0)$ \\
\hline
\end{tabular}


Table 2.2: Mean ROI $\mathrm{K}^{2}$ trans $\mathrm{rCBF}$ and $\mathrm{rCBV}$ values prior to, 1 week and 1 month following radiation. Comparison of $\mathrm{PD}$ vs. non-PD (CR, $\mathrm{PR}, \mathrm{SD})$ and tumor response (CR, PR) vs. non-response ( $\mathrm{PD}, \mathrm{SD})$. $\mathrm{P}$ values were obtained using non-parametric Mann-Whitney univariate analysis.

\begin{tabular}{|c|c|c|c|c|c|c|}
\hline & PD & $\begin{array}{c}\text { Non-PD } \\
(\mathrm{CR}, \mathrm{PR}, \mathrm{SD})\end{array}$ & $\begin{array}{c}\text { Tumor } \\
\text { Resp. } \\
\text { (CR, PR) } \\
\end{array}$ & $\begin{array}{c}\text { Tumor } \\
\text { Non-Resp. } \\
(\mathrm{PD}, \mathrm{SD})\end{array}$ & $\begin{array}{c}\text { PD vs. } \\
\text { Non-PD } \\
(\mathrm{CR}, \mathrm{PR}, \mathrm{SD}) \\
\end{array}$ & $\begin{array}{l}\text { Resp. vs. } \\
\text { Non-Resp. } \\
\text { (PD, SD) }\end{array}$ \\
\hline & $\mathbf{K}_{\text {trans }}^{2}$ & & & & P-Values & P-Values \\
\hline Baseline & $1.74 \pm 0.73$ & $1.78 \pm 0.81$ & $1.67 \pm 0.78$ & $1.85 \pm 0.71$ & 0.985 & 0.261 \\
\hline 1 week & $2.33 \pm 1.06$ & $2.13 \pm 1.25$ & $1.67 \pm 1.16$ & $2.52 \pm 1.14$ & 0.491 & $0.003^{*}$ \\
\hline \multirow[t]{2}{*}{1 month } & $2.19 \pm 1.07$ & $2.26 \pm 1.33$ & $1.87 \pm 1.47$ & $2.46 \pm 1.13$ & 0.85 & 0.063 \\
\hline & $\mathrm{rCBF}$ & & & & P-Values & P-Values \\
\hline Baseline & $2.33 \pm 1.06$ & $3.00 \pm 1.22$ & $2.74 \pm 1.19$ & $3.02 \pm 1.23$ & 0.063 & 0.434 \\
\hline 1 week & $1.76 \pm 3.03$ & $1.61 \pm 2.20$ & $1.09 \pm 0.88$ & $2.06 \pm 2.96$ & 0.465 & $0.041^{*}$ \\
\hline \multirow[t]{2}{*}{1 month } & $2.47 \pm 1.90$ & $3.41 \pm 1.48$ & $2.70 \pm 1.16$ & $3.49 \pm 1.73$ & $0.048^{*}$ & 0.128 \\
\hline & $\mathrm{rCBV}$ & & & & P-Values & P-Values \\
\hline Baseline & $2.87 \pm 0.79$ & $3.47 \pm 1.14$ & $3.19 \pm 1.13$ & $3.50 \pm 1.09$ & 0.145 & 0.213 \\
\hline 1 week & $4.10 \pm 2.81$ & $4.03 \pm 2.46$ & $3.71 \pm 1.72$ & $4.29 \pm 2.94$ & 0.993 & 0.916 \\
\hline 1 month & $2.23 \pm 1.68$ & $3.78 \pm 1.70$ & $3.15 \pm 1.72$ & $3.71 \pm 1.72$ & $0.008^{*}$ & 0.263 \\
\hline
\end{tabular}




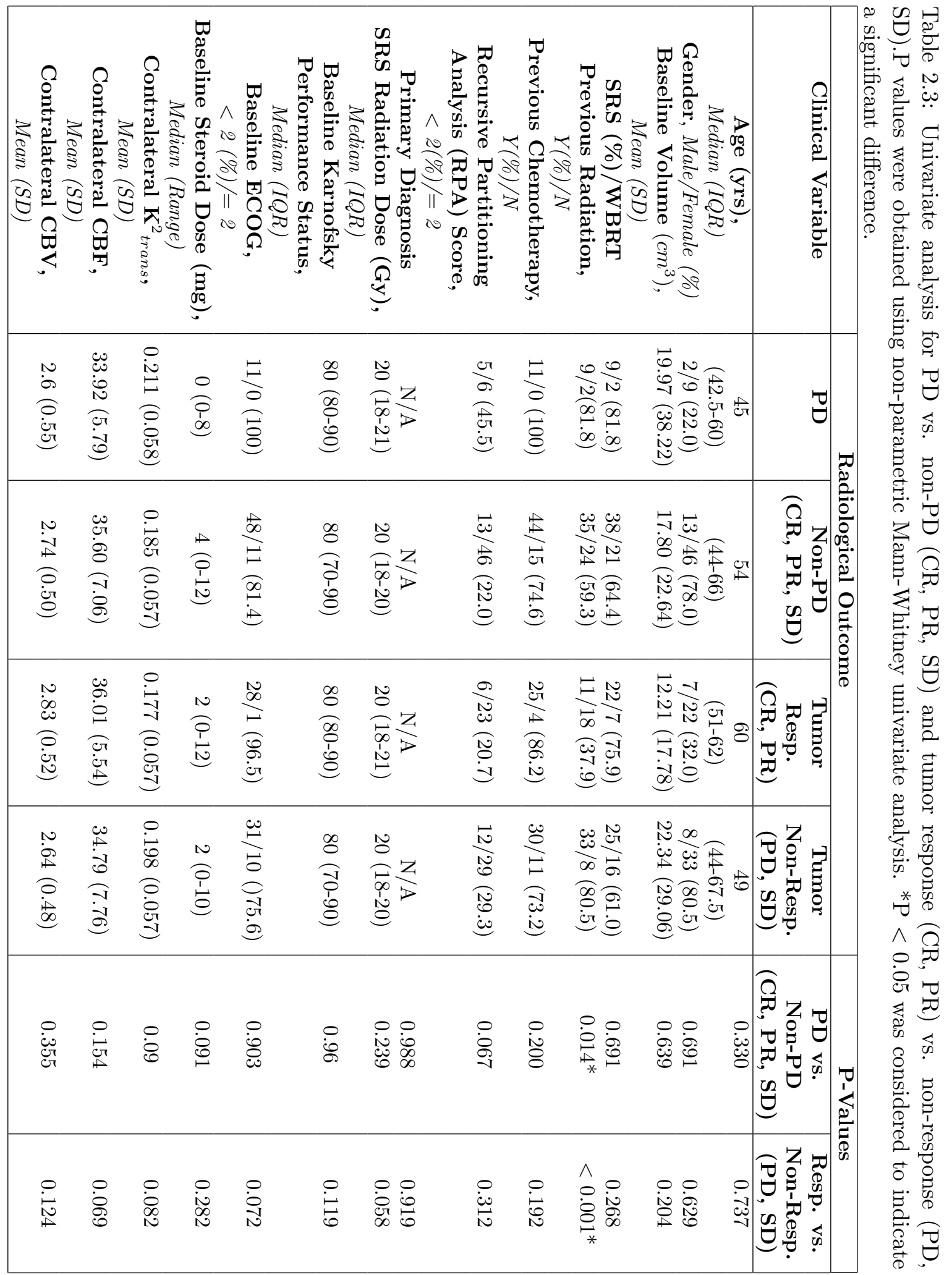


Table 2.4: Multivariate logistic regression distinguishing responders (CR, PR) from nonresponders (PD, SD) using $\mathrm{K}_{\text {trans }}^{2}$ tumor permeability and distinguishing $\mathrm{PD}$ from non-PD (SD, PR, CR) using rCBV.

\begin{tabular}{c|c|c}
\multicolumn{3}{c}{$\mathbf{K}_{\text {trans }}^{2}$ Model } \\
\hline Variable & Odds Ratio (95\% CI) & P-Value \\
\hline $\mathbf{K}^{2}{ }_{\text {trans }}$ 1 week & $1.91(1.08-3.36)$ & $0.026^{*}$ \\
Previous Radiation & $0.13(0.04-0.43)$ & $0.001^{*}$
\end{tabular}

rCBV Model

\begin{tabular}{c|c|c}
\hline \hline Variable & Odds Ratio (95\% CI) & P-Value \\
\hline rCBV 1 month & $0.444(0.243-0.812)$ & $0.008^{*}$ \\
Previous Radiation & $0.156(0.022-1.084)$ & 0.06
\end{tabular}

*Significant result $(\mathrm{P}<0.05)$ 


\section{Chapter 3}

\section{Normal Brain Tissue Response}

This chapter presents an analysis of normal brain tissue perfusion response to SRS study entitled "Non Tumor Perfusion Changes Following Stereotactic Radiosurgery to Brain Metastases". This work comprises a manuscript under review in Technology in Cancer Research and Treatment Express at time of thesis submission.

\section{Non Tumor Perfusion Changes Following Stereotactic Radiosurgery to Brain Metastases}

Raphael Jakubovic B.Sc. ${ }^{1,2}$, Arjun Sahgal M.D. ${ }^{3}$, Mark Ruschin Ph.D. ${ }^{3}$, Ana PejovićMilić Ph.D. ${ }^{2}$, Rachael Milwid ${ }^{1}$, Richard I Aviv MRCP, FRCR, FRCPC ${ }^{1}$

${ }^{1}$ Department of Medical Imaging, Division of Neuroradiology, Sunnybrook Health Sciences Centre, University of Toronto, Toronto, Ontario, Canada

${ }^{2}$ Department of Biomedical Physics, Ryerson University, Toronto, Ontario, Canada

${ }^{3}$ Department of Radiation Oncology, Odette Cancer Centre of the Sunnybrook Health Sciences Centre, University of Toronto, Toronto, Ontario, Canada 


\subsection{Abstract}

Purpose: To evaluate early perfusion changes in normal tissue following SRS.

Methods: Nineteen patients harboring twenty-two brain metastases treated with SRS were imaged with DSC MRI at baseline, 1 week and 1 month post SRS. rCBV and rCBF ratios were evaluated outside of tumor within a combined region of interest and separately within GM and WM ROIs. Three-dimensional dose distribution from each SRS plan was divided into six regions: (1) < 2 Gy; (2) 2-5 Gy; (3) 5-10 Gy; (4) 10-12 Gy; (5) 12-16 Gy; and (6) $\geq 16$ Gy. rCBV and $\mathrm{rCBF}$ ratio differences between baseline, 1 week and 1 month were compared. Best linear fit plots quantified normal tissue dose-dependency.

Results: Significant rCBV ratio increases were present between baseline and 1 month for all ROIs and dose ranges except for WM ROI receiving $<2$ Gy. rCBV ratio for all ROIs was maximally increased from baseline to 1 month with the greatest changes occurring within the 5-10 Gy dose range. $\mathrm{rCBF}$ ratio was maximally increased from baseline to 1 month for all ROIs within the 5-10 Gy dose range. Both rCBV and rCBF ratios were most elevated within GM ROIs. A weak, positive but not significant association between dose, rCBV and $\mathrm{rCBF}$ ratio was demonstrated. Progressive rCBV and $\mathrm{rCBF}$ ratio increased with dose up to 10 Gy at 1 month.

Conclusion: Normal tissue response following SRS can be characterized by dose, tissue, and time specific increases in $\mathrm{rCBV}$ and $\mathrm{rCBF}$ ratio. 


\subsection{Introduction}

SRS is commonly used to treat cerebral metastases. SRS is the delivery of a single high total dose of radiation to a target localized in three dimensions with millimetre precision. SRS has the benefit of increasing tumor control compared to WBRT, but at the expense of a greater risk of radiation-induced necrosis (Minniti et al., 2011). Little data is available on the long term effects of radiation due to limited survival, but it has been estimated that at least $10 \%$ of patients that survive over 12 months develop dementia, ataxia and urinary incontinence (Arnold and Patchell, 2001). Side effects include acute headaches, nausea, and drowsiness, subacute neurological deterioration and late development of necrosis, worsening neurological status, seizures, and increased intracranial pressure (Constine et al., 1988; Tsuruda et al., 1987). Predictive factors of necrosis have indicated that the dose delivered to normal brain tissue surrounding the targeted tumor is critical [for example, the volume exposed to 10 Gy (V10) or 12 Gy (V12)] (Minniti et al., 2011).

The physiological response of normal tissue to radiation, considered a surrogate of cellular response and dose tolerance, has been shown to differ based on whether there is a single high dose exposure or multiple sessions delivering a fractionated dose Burnet et al., 1998; Wood et al., 2005). SRS mitigates the extent of normal tissue damage by delivering an ablative dose to the tumor coupled with rapid dose fall-off. The efficacy of SRS for metastases is well documented with reported local control $>80 \%$ in over 2000 treated patients (Loeffler et al., 1999). Perfusion imaging is widely used as a surrogate of tumor response in primary and secondary tumors (Bulakbasi et al., 2005, Cao et al., 2006; Cao et al., 2009; Essig et al., 2003; Millar et al., 2005). Few studies have evaluated perfusion response within normal tissues following radiotherapy. A better understanding of the radiobiological effects of SRS specifically in normal brain tissue would provide insight into tissue specific dose tolerances and potentially guide isodose prescription. Our aim was to determine the physiologic changes within the surrounding normal brain tissue following exposure to SRS using DSC MRI perfusion derived parameters. 


\subsection{Methods}

\subsubsection{Study Design and Patient Cohort}

Nineteen patients treated with SRS were enrolled between March 2008 and April 2011 on an institutional research ethics board approved protocol. Inclusion criteria included brain metastases treated with SRS, age $\geq 18$, able to provide consent for the MRI protocol, diagnosis of brain metastases, expected life expectancy greater than 6 months, and KPS greater than 70. Patients with MRI contraindications, prior allergic reaction to gadolinium, or a treatment plan including WBRT were excluded. Baseline clinical parameters recorded included age, gender, tumor volume, radiation dose, steroid administration, RPA score, KPS, and ECOG performance status.

\subsubsection{Imaging Acquisition}

DSC MRI was performed at baseline, one week and one month following treatment. Structural MRIs were performed every two months thereafter. MRI brain sequences were performed on a $1.5 \mathrm{~T}$ GE Twinspeed (General Electric, Mississauga, Canada) and included a DWI $(7000 \mathrm{~ms} / \mathrm{min}$ [TR/TE], FOV of $24 \mathrm{~cm}$, matrix $128 * 128$, section thickness of $5 \mathrm{~mm}$ with no gap); a FLAIR image (8000/120/200 [TR/TE/TI], FOV $24 \mathrm{~cm}$, matrix 320*224, ST 5, 1 mm gap); a sagittal T1 FLAIR image (2200/24/750 [TR/TE/TI], FOV $24 \mathrm{~cm}$, matrix $224^{*} 320$, NEX 2, ST $5 \mathrm{~mm}, 1 \mathrm{~mm}$ spacing); a 3D T1 SPGRE (8.5/4.2, FA 20, FOV $22 \mathrm{~cm}$, matrix 270*270, NEX 2) and a DSC study (1700/31.5/90, FOV 24 $\mathrm{cm}$; section thickness $5 \mathrm{~mm}$; matrix $128 * 128$; no gap). Gadovist $0.1 \mathrm{ml} / \mathrm{kg}, 1 \mathrm{mmol} / \mathrm{l}$ concentration was injected at $5 \mathrm{~mL} / \mathrm{s}$ for the DSC study. The DSC study was followed by a post-gadolinium 3D T1 FSPGRE with similar parameters to pre-gadolinium sequence.

\subsubsection{Radiation Treatment}

All patients were treated with SRS alone. The T1 MR images were fused to the stereotactically localized CT images for planning. Treatment planning was performed using the Radionics planning software (Integra Radionics, Burlington, Massachusetts, United States) with radiation doses ranging from 16 Gy to 24 Gy in a single fraction. SRS dose selection was based according to tumor diameter in accordance to RTOG 9005 
(Shaw et al., 2000). Localization and immobilization was performed using the BrownRoberts-Wells head frame. Treatment delivery was performed using $6 \mathrm{MV}$ photons on a Siemens PRIMUS linear accelerator (Siemens AG, Erlangen, Germany), equipped with stereotactic cones ranging from $1.0 \mathrm{~cm}$ in diameter up to $4.0 \mathrm{~cm}$ in diameter.

\subsubsection{Image Analysis}

\section{SRS Dose Distribution Determination}

Pre-treatment SRS localized dose planning CT images with overlaid isodose maps were co-registered to structural 3D T1 SPGRE post-gadolinium images. All co-registrations were performed using a tri-linear interpolation algorithm using SPM12b (Welcome Trust, London, United Kingdom).

\section{MR Images}

Tumor volumes were measured using MIPAV (Medical Image Processing, Analysis and Visualization software; Center for Information Technology, National Institutes of Health, version 4.4.1.). A brain tissue probability map template (Montreal Neurological Institute, Montreal, Canada) comprising GM, WM, and CSF was co-registered to the baseline structural T1-post gadolinium images using SPM12b. GM and WM tissue binary masks were generated by applying a 50\% threshold to the registered tissue probability maps. DSC maps were calculated with positron emission tomography validated software utilizing SVD (Kudo et al., 2003). DSC maps were co-registered to structural T1-post gadolinium images. Voxels containing CBV $>8 \mathrm{~mL} / 100 \mathrm{~g}$ or $\mathrm{CBF}>100 \mathrm{~mL} / 100 \mathrm{~g} / \mathrm{min}$ were excluded as previously described (Murphy et al., 2006). A contra-lateral mirror region was reflected and used to calculate $\mathrm{rCBV}$ and $\mathrm{rCBF}$ values.

\section{Dosimetric Analysis}

Three-dimensional volume assessments were performed for all marker lesions at all time-points using MIPAV using 3D T1 SPGRE images. Co-registered SRS dose plans were segmented using in-house software developed within MATLAB (MATLAB 2012b, The MathWorks, Inc., Natick, Massachusetts, United States) and superimposed on the 
rCBV and rCBF maps. The following six irradiated dose levels were defined: $<2$ Gy and 2-5 Gy (out of target), 5-10 Gy, 10-12 Gy, and 12-16 Gy (peri-target), and $\geq 16$ Gy (on target). Tumor voxels were removed from analysis. A typical dose distribution is shown in Figure 3.1. Combined ROIs included both GM and WM. Thresholded tissue probability maps were used to divide combined ROIs further into individual GM and WM ROIs. Percent of total intracranial volume of combined, GM and WM for each dose level were calculated based on intracranial volumes calculated using Individual Brain Atlases using Statistical Parametric Mapping software (IBASPM, Cuban Neuroscience Center, Playa, Ciudad de la Habana, Cuba) (Alemán-Gómez Y., Melie-García L., 2006).

\subsubsection{Statistical Analysis}

For each SRS dose level and MRI time point, CBF and CBV were extracted from the DSC maps for combined, GM and WM ROIs and expressed as a ratio relative to the contralateral baseline. rCBV and rCBF ratio change between baseline and 1 week and baseline and 1 month for each dose level for combined, GM, and WM were compared using the Wilcoxon signed ranks test. Dose was plotted against rCBV and rCBF ratio for combined, GM, and WM ROIs and a best line linear fit was applied to each set of data. All analyses were performed using SPSS version 21. $\mathrm{P}<0.05$ was considered significant.

\subsection{Results}

Baseline tumor and patient characteristics for the 19 patients and 22 metastases treated are described in Table 3.1. Median (range) SRS dose was 20 Gy (16-24 Gy) in a single fraction. Mean (SD) intracranial brain volume was $23.52(3.87) \mathrm{cm}^{3}$. The percent of irradiated intracranial volume for each dose level is shown in Table 3.2. rCBV and rCBF ratio stratified by dose for combined, GM and WM ROIs are provided in Table 3.3 and Figure 3.2.

rCBV ratio increased between baseline and 1 week for all ROIs and dose ranges although the increase was not statistically significant. Significant rCBV ratio increase was present between baseline and 1 month for all ROIs and dose ranges with the exception of the WM ROI receiving $<2$ Gy. rCBV ratio for all ROIs was maximally increased from baseline at 1 month with the greatest changes occurring within the 5-10 Gy dose range. 
Table 3.1: Baseline clinical variables $(\mathrm{n}=19$ patients, 22 indexed tumors $)$

\begin{tabular}{c|c} 
Clinical Variable & N (\%) \\
\hline \hline Male Gender: & $10(52.6)$ \\
Previous Radiation: & $9(47.4)$ \\
Previous Chemotherapy: & $15(78.9)$ \\
Recursive Partitioning & \\
Analysis Score (RPA): & $6(31.6)$ \\
1 & $1(5.3)$ \\
2 & $12(63.1)$ \\
3 & Median (range) \\
Radiation Dose (Gy): & $20(16-24)$ \\
Baseline Karnofsky Performance & $80(80-90)$ \\
Status (KPS) Median (IQR): & $17(89.5)$ \\
Baseline ECOG < 2: & $8(42.1)$ \\
Steroids at Baseline: & $5(26.3)$ \\
Primary Tumor Diagnosis: & $2(10.5)$ \\
Melanoma & $8(42.1)$ \\
Breast & $3(15.8)$ \\
Lung & $1(5.3)$ \\
Renal Cell &
\end{tabular}

Table 3.2: Percent of irradiated intracranial volume for each dose level calculated using IBASPM.

\begin{tabular}{c|c|c|c|c|c|c}
$\mathbf{\%}$ & $\geq \mathbf{1 6}$ Gy & $\mathbf{1 2 - 1 6}$ Gy & $\mathbf{1 0 - 1 2} \mathbf{~ G y}$ & $\mathbf{5 - 1 0}$ Gy & $\mathbf{2 - 5} \mathbf{~ G y}$ & $<\mathbf{2}$ Gy \\
\hline \hline Combined & $0.094 \pm 0.086$ & $0.063 \pm 0.045$ & $0.064 \pm 0.048$ & $0.525 \pm 0.440$ & $2.973 \pm 2.264$ & $96.27 \pm 2.852$ \\
$\mathbf{G M}$ & $0.141 \pm 0.148$ & $0.150 \pm 0.128$ & $0.111 \pm 0.102$ & $0.786 \pm 0.768$ & $3.333 \pm 2.284$ & $95.47 \pm 3.326$ \\
$\mathbf{W M}$ & $0.039 \pm 0.031$ & $0.042 \pm 0.029$ & $0.035 \pm 0.026$ & $0.330 \pm 0.310$ & $1.906 \pm 1.566$ & $97.64 \pm 1.925$
\end{tabular}


GM ROI rCBV ratio values were most elevated.

rCBF ratio increase occurred within the combined ROI between baseline and 1 week in the $>10$ Gy dose range. This was driven predominantly by GM changes at the higher dose ranges. $\mathrm{rCBF}$ ratio increased between baseline and 1 month for combined ROIs across all dose ranges although the increase was not significant. Significant rCBF ratio increase was however present at 1 month for GM dose ranges $>10$ Gy and WM dose ranges between 5 and 16 Gy. rCBF ratio for all ROIs was maximally increased from baseline at 1 month with the greatest changes occurring within the 5-10 Gy dose range. GM ROI rCBF ratio values were most elevated.

A weak, positive but not significant association between dose, $\mathrm{rCBV}$ and $\mathrm{rCBF}$ ratio at 1 week and 1 month for all ROIs was demonstrated (Figure 3.3; rCBV: $\rho=0.027$ 0.114; rCBF: $\rho=0.042-0.135)$. rCBV and rCBF ratio increased progressively with dose between baseline and 1 week driven predominantly by GM changes. rCBV and rCBF ratio WM ROI increases were also seen but attenuated beyond $10 \mathrm{~Gy}$. At 1 month nonsignificant progressive rCBV and rCBF ratio increase occurred for all ROIs up to $10 \mathrm{~Gy}$.

\subsection{Discussion}

We demonstrate $\mathrm{rCBV}$ and $\mathrm{rCBF}$ ratios increasing in the adjacent normal brain tissues following SRS to brain metastases. These changes were maximal at 1 month and within the 5-10 Gy dose range (Fig $3.2(\mathrm{~B}, \mathrm{D})$ ). Progressive increases with dose were present, although the correlation was weakly positive due to a ceiling effect observed at 10 Gy. The highest rCBV and rCBF ratio increase was present in GM ROIs with sparing of WM in the $<2$ Gy dose range.

The results of our study indicate that early SRS tissue response within normal tissues occurs in a dose, tissue, and time specific manner. rCBV and rCBF ratios could be surrogates of endothelial apoptosis, vascular damage and radionecrosis, and may provide a framework for the delineation of GM and WM tissue-specific dose tolerances in normal tissue and the integration of these tolerances into an isodose prescription. Further study with repeated imaging and clinical/radiographic response is required and now underway at our institution. 
Our results also highlight the dose-sparing effect of SRS with over $96 \%$ of the total intracranial volume receiving $<2$ Gy of radiation (Table 3.2) with no early WM perfusion changes seen following SRS (Table 3.3) in the low dose region. This is consistent with sparing of a significant volume of normal tissue from SRS related effects. However, increased GM ROI rCBV ratio was present even in the $<2$ Gy dose range reflecting greater radiation perfusion response of these regions presumably due to higher metabolic demand (Wenz et al., 1996; Fuss et al., 2000). Supporting these findings, WM ROI rCBV and $\mathrm{rCBF}$ increase was previously shown in regions receiving $<2$ Gy following a single fraction of WBRT (Price et al., 2007). Preferential GM ROIs rCBV involvement was also previously shown in a study reporting a reduction at 6 months following fractionated conformal and whole brain radiotherapy (Wenz et al., 1996; Fuss et al., 2000). The prior findings and present study results are consistent with early acute $\mathrm{rCBV}$ and rCBF ratio increases with preferentially GM involvement followed by later reduction. The precise biological cause and pathophysiological nature of these GM rCBV ratio changes remains unclear.

The response to SRS of normal tissue is largely unknown and perfusion response is varied (Taki et al., 2002; Weber et al., 2003). We demonstrate an incremental rCBV and rCBF ratio increase with dose up to 10 Gy. Several time and dose dependant biological mechanisms in normal tissues are associated with increasing radiation dose including vessel dilation, endothelial cell death and apoptosis (Cao, 2011). Endothelial apoptosis and subsequent cell death begins within twenty-four hours of irradiation and continues up to 1 month followed by a dose independent decrease in cell density up to 6 months (Ljubimova et al., 1991; Peña et al., 2000).

rCBV and $\mathrm{rCBF}$ ratio was maximal at 1 month with a progressive increase with dose and ceiling effect at 10 Gy (Figure 3.2 and Table 3.3). Maximum dose effect was seen between 5-10 Gy. Whereas doses of 2-5 Gy and 5-12 Gy have been shown to be effective in direct death of oxygenated and hypoxic cells respectively, doses higher than 10-12 Gy induce indirect cell death via vascular damage (Minniti et al., 2011; Milano et al., 2011; Song et al., 2012). A rapid increase in vascular volume and permeability over the course of fractionated partial brain radiotherapy followed by a rapid drop-off by 1 month after treatment has also been shown to occur in a dose and time dependent fashion resulting in vascular regression (Cao et al., 2009). This regression is attributed to capillary 
collapse and/or occlusion caused by endothelial cell death, and is referred to as vessel renormalization. This suggests that regions with greater vascular damage would exhibit an earlier perfusion response followed by vascular regression in regions receiving $>10 \mathrm{~Gy}$ by 1 month.

Limitations of this study include the administration of previous radiation and chemotherapy, lack of control for dexamethasone dose beyond the 1 week scan, and heterogeneity of tumor types. Patient life expectancy, particularly in a cohort of metastatic brain lesions further limited our ability to assess the association between normal tissue response and radio-necrosis. Although the patient cohort studied represents the largest perfusion cohort reported to date, statistical power was limited by the number of patients. The magnitude of change for each tissue type was modest and insufficient to discriminate individual dose ranges although a preferential increase in GM was seen. In conclusion we observed time, dose, and tissue specific increases in rCBV and rCBF ratio within normal tissue driven predominantly by GM change. Sparing of significant volume of WM receiving $<2$ Gy was identified. Further study is required to investigate whether these biomarkers reflect an increased risk of radionecrosis in normal tissue. 


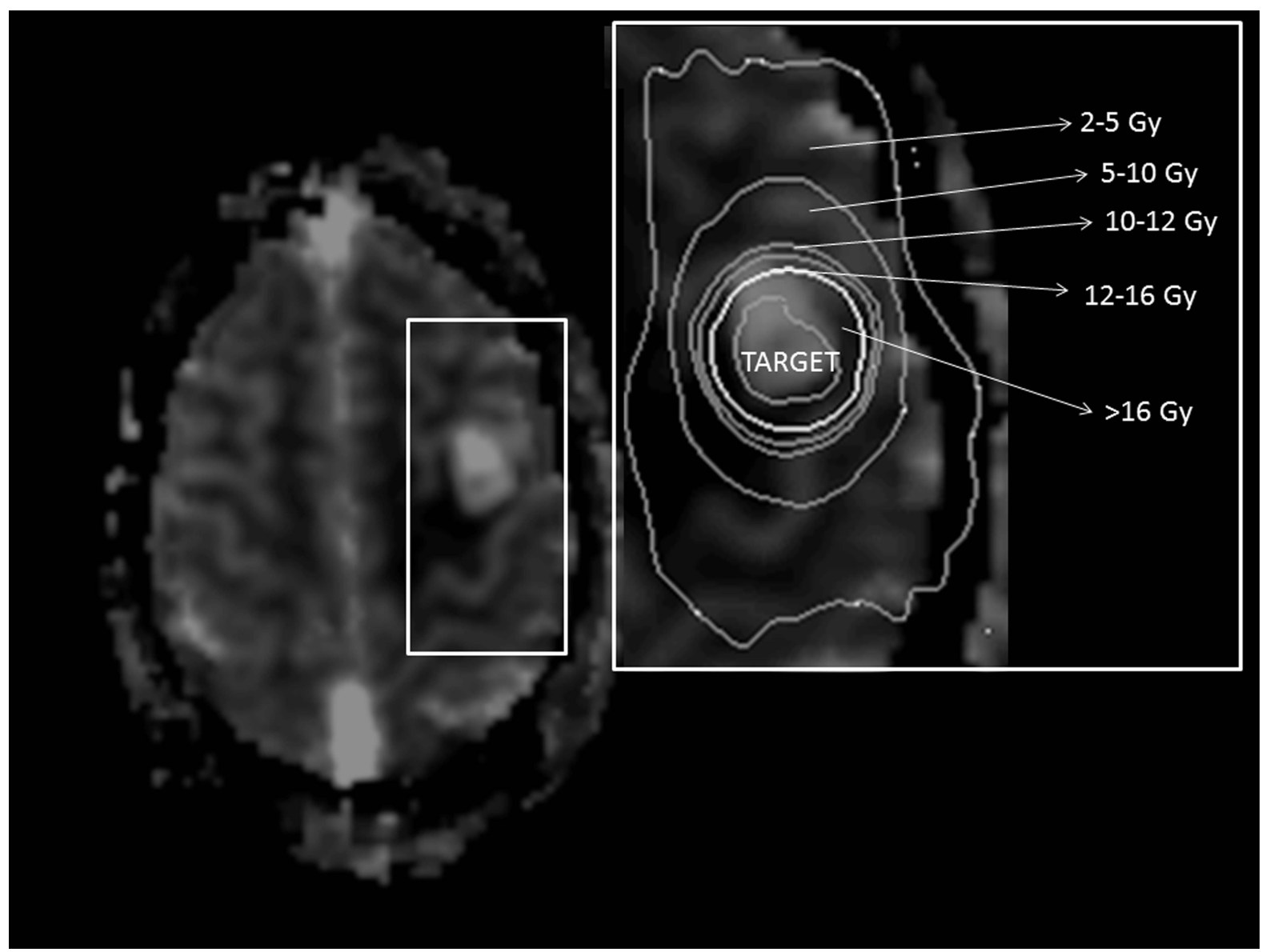

Figure 3.1: CBV with overlaid dose distribution: 71 year old male patient (KPS 90) diagnosed with brain metastases secondary to colon carcinoma and treated with 18 Gy SRS. Single lesion located in the left precentral gyrus. Target region is drawn for illustrative purposes but was excluded from analysis. 

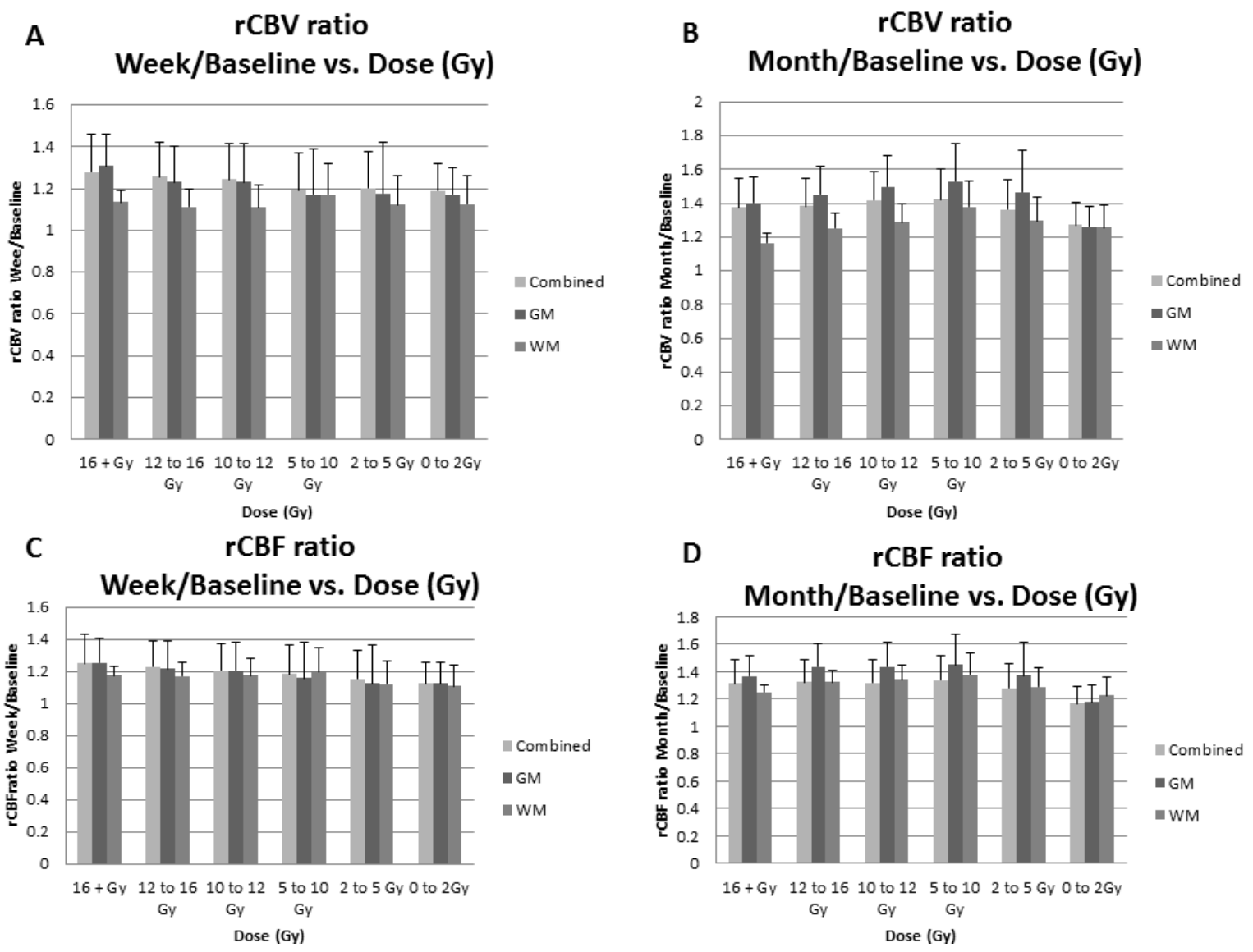

Figure 3.2: Mean and standard error rCBV and $\mathrm{rCBF}$ ratio for combined, GM and WM ROIs at each SRS dose level at 1 week (week/baseline) (A,C) and 1 month (month/baseline) following radiation. (B,D) 


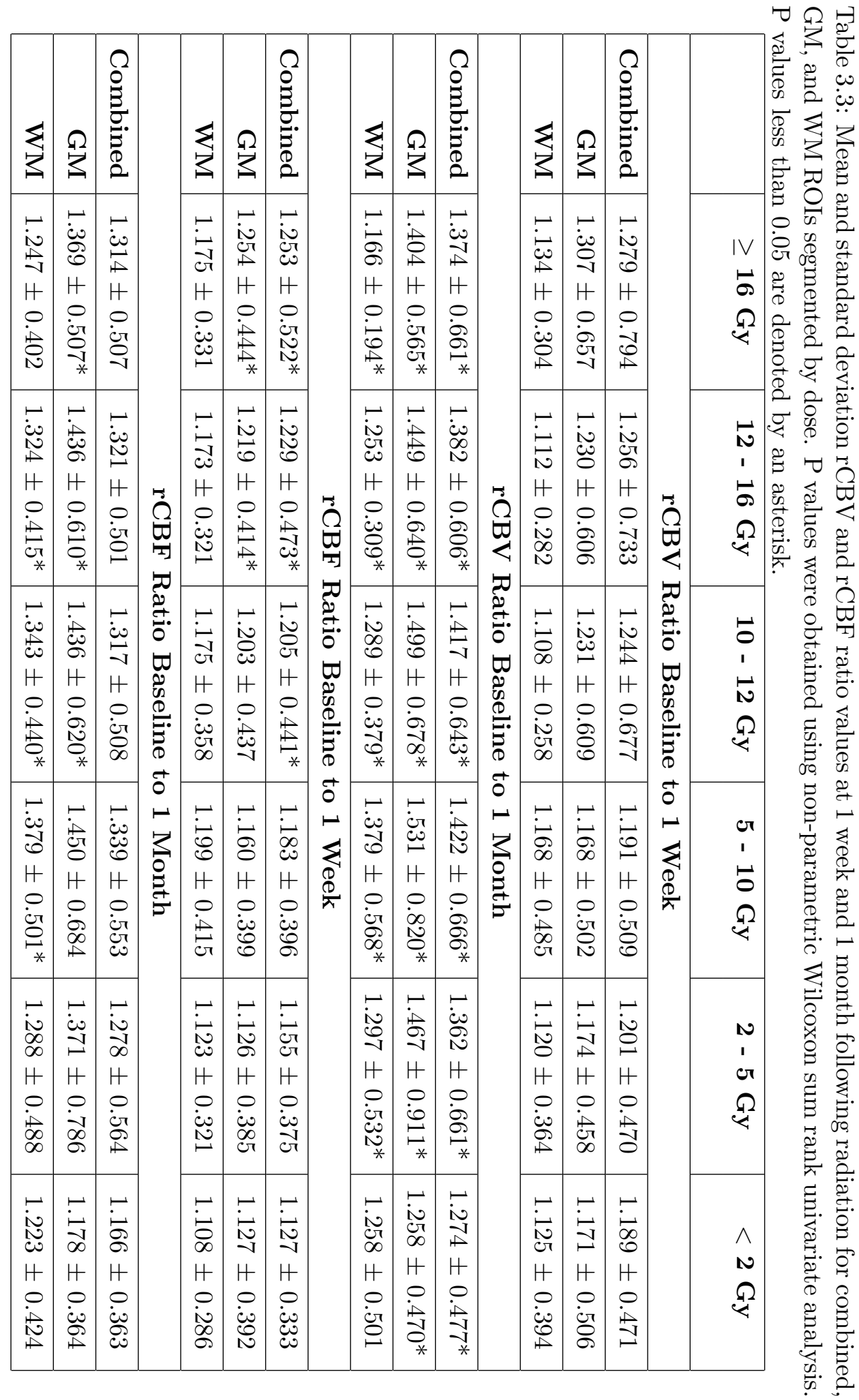



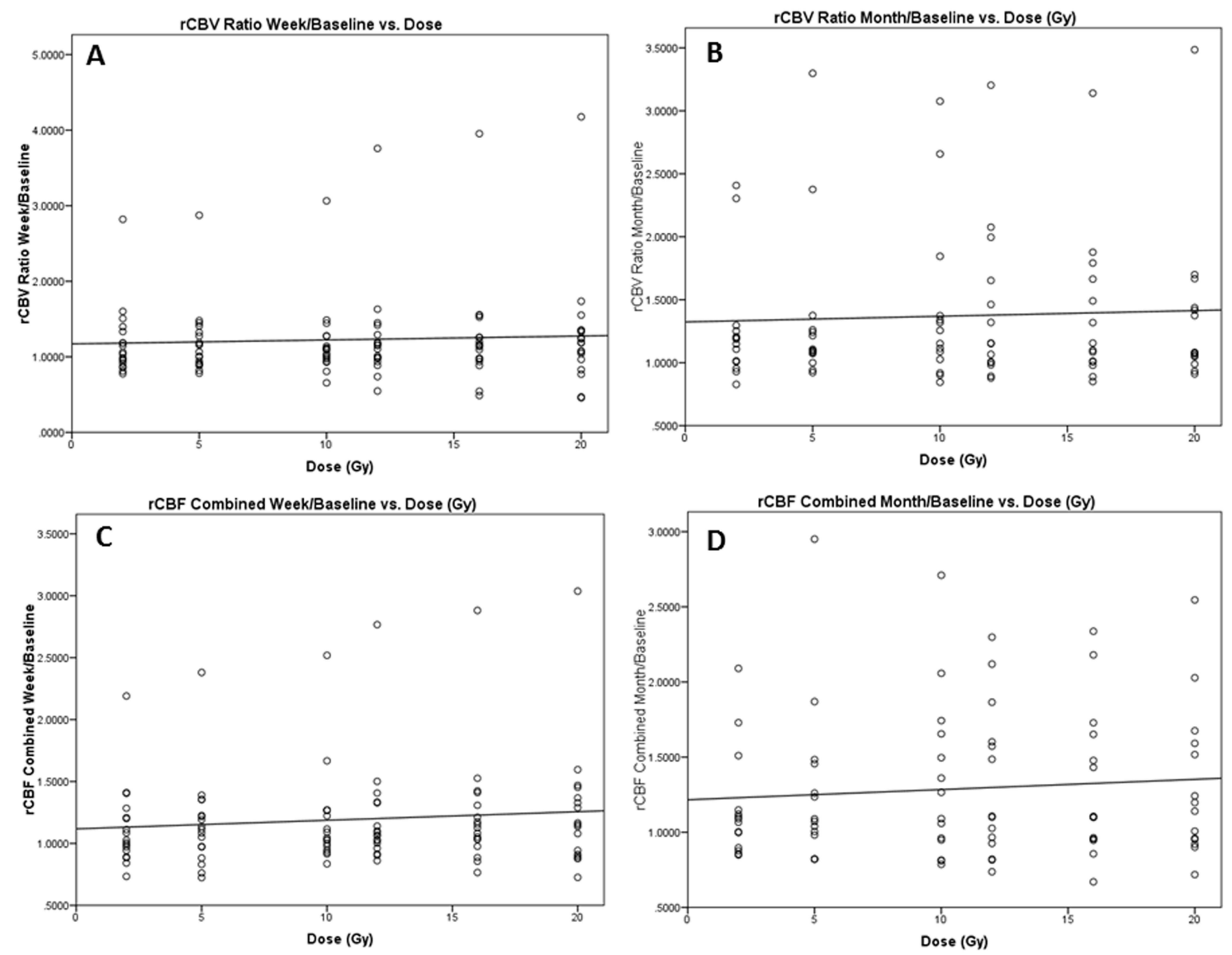

Figure 3.3: Line of best fit for combined $\mathrm{rCBV}$ and $\mathrm{rCBF}$ ratio. (A,B) rCBV and (C, D) rCBF ratio Week/Baseline and Month/Baseline. A weak positive correlation for all tissue types for dose and perfusion was demonstrated. 


\section{Chapter 4}

\section{Discussion and Conclusions, Limitations, and Future Work}

\subsection{Discussion and Conclusions}

This thesis presents the only analysis of DCE MRI-derived $\mathrm{K}_{\text {trans }}^{2}$ in metastatic disease of the brain and the largest analysis of DSC MRI metastatic brain tumor response with SRS or WBRT. This thesis also presents the largest analysis of DSC MRI normal tissue response specific to metastases treated with SRS. Strengths include rigorous imaging protocols and maintenance of tightly controlled steroid doses as far as clinically possible between baseline and 1 week.

Chapter 2 presents an analysis of early metastatic tumor response using DCE MRI and DSC MRI following SRS and WBRT. Our results quantify early functional changes within metastases and the prediction of disease progression or treatment response. The results of this study showed increased $\mathrm{K}^{2}$ trans at 1 week as a predictor of treatment non-response and decreased $\mathrm{rCBV}$ as a predictor of tumor progression. Optimal cut-off values of 1.37 for $\mathrm{K}_{\text {trans }}^{2}$ above which indicate tumor progression and 2.03 for $\mathrm{rCBV}$ above which indicate treatment response provide useful physiological parameters which can be incorporated into clinical care.

The importance of physiological imaging parameters in diagnosis and treatment is highlighted within the glioma literature. In particular DSC MRI is able to evaluate glioma grade, tumor outcome, tumor necrosis and patient survival Aronen et al., 1994; 
Law et al., 2002; Law et al., 2008). Vascular leakiness as measured by DCE MRI-derived $\mathrm{K}_{\text {trans }}^{2}$ evaluates tumor grade, predicts patient outcome, and is considered a surrogate of tumor aggressiveness and/or tumor necrosis (Jain, 2013). Use of these measures have enabled accurate glioma grading and allowed for targeted biopsy localization (Jain, 2013). Our results highlight the possibility that DSC and DCE MRI data shown in glioma can be effectively translated into a metastatic brain tumor cohort. Preliminary results indicate a strong need for larger datasets that would permit tumor specific threshold determination.

The ability to discern treatment response or disease progression at a very early stage in treatment has profound clinical impact. MR perfusion and permeability implementation within an early timeframe is particularly useful as it provides the basis for possible treatment interventions. For example, tumors with increased $\mathrm{K}_{\text {trans }}{ }$ at 1 week or decreased rCBV at 1 month would receive further radiation treatment due to their increased odds of progression or non-response. Alternatively, these tumors can be targeted with vascular inhibiting agents such as bevacizumab or surgically excised. Tumors predicted to respond would be prescribed sole modality therapy thereby avoiding the potential risks of further treatment. Integration of this physiological information into clinical practice can be used to stratify patients at risk of progression and guide treatment course.

Chapter 3 presents analysis of normal brain tissue response using DSC MRI following SRS. Within normal brain tissue our results indicate that early perfusion increases from baseline to 1 week and baseline to 1 month occur in a dose, time and tissue dependent manner. These results highlight the potential utility of functional MRI in determining patient, dose and tissue specific radiation tolerances and its integration into dose prescription. Further study is required to determine the effectiveness of these biomarkers in a larger patient cohort and whether these surrogates can guide clinical decisions.

The characterization of perfusion changes in normal brain following SRS is especially beneficial as a tool to stratify risk of radiation response and/or necrosis. Tissue tolerances play an integral role in dose prescription and therefore limit the amount of radiation delivered to the tumor. The narrow range of changes seen at various dose ranges provides a challenge for current clinical implementation. A larger dataset controlling for tumor histology would minimize the standard deviation and possible detect differences within each dose level. 
These results also highlight the dose-sparing effect of SRS. This development is encouraging and indicates the usefulness of SRS in minimizing radiation dose to normal brain tissue. With recent technological advances and the use of highly conformal radiation therapy, it is conceivable that functional imaging can be utilized in an acute setting in order to guide an adaptive treatment setting based on physiological parameters derived from MR perfusion. The ability to tailor dose delivery track dynamic changes with physiological imaging provides the basis for real-time adjustments and assessments of normal tissue response. This information can potentially be used to minimize dose in radiosensitive tissues, limiting normal tissue damage and impacting overall QOL.

This work provides the framework for the prediction of tumor outcome within 1 week and 1 month following treatment. Early increases in perfusion following SRS are detected and provide an early physiological assessment of normal tissue response to radiation. Efforts to expand this dataset are currently underway at our centre.

\subsection{Limitations}

There were several limitations to these studies including a heterogeneous subset of tumors, varying treatment regimens, lack of control for dexamethasone dose beyond 1 week and short survival times. Although primary tumor histology is a limiting factor, majority of tumors studied were comprised of hyperperfused and hyperpermeable lesions originating from breast, lung and melanoma. Control of dexamethasone dose mitigated steroid related changes immediately following treatment, but was not controlled beyond 1 week. This limitation is common to most similar studies as it is impractical to maintain long term steroid doses due to the potential adverse effects.

Although the patient cohort studied represents the largest studied to date, the number of metastases available for subgroup analysis remains a limitation. Future studies should harmonize clinical factors including administration of previous brain radiation and/or chemotherapy in subgroup analyses. Previous treatment would impact both tumor and normal tissue perfusion and permeability and therefore varying responses are expected. Subgroup analysis and exclusion cannot be applied to our cohort due to limited sample size. 
Typical of studies in patients with metastases, poor long term survival hampered our ability to assess long term tumor response or progression. Response was determined 1 year post treatment, despite the possibility of progression in patients surviving beyond this period. The short survival times limited the number of tumors diagnosed as progressive disease reducing the statistical power of our cohort. Similarly limited survival times impacted our ability to discern normal tissue damage and radio-necrosis. Long term follow-up is necessary to determine the whether early perfusion response indicates ongoing endothelial apoptosis and radiation damage. A more rigorous subgroup analysis by metastasis type cannot be performed in the present cohort but should be considered in future work.

\subsection{Future Work}

This study lays the groundwork for future studies involving functional MR imaging. A more robust analysis allowing for subset analysis and limiting recruitment to patients with 4 brain metastases, no prior radiation treatment and life expectancy $>1$ year would reinforce these results and reduce variability within our cohort attributed to a diverse patient population. Limited survival times remain a concern in brain metastases and future work should focus on determining feasible, clinically relevant endpoints. Prospective validation of the $\mathrm{K}^{2}$ trans and $\mathrm{rCBV}$ thresholds would be a logical next step toward the integration of functional MRI into clinical practice.

Future study should also focus on the derivation of tissue specific dose tolerances using predefined clinically relevant endpoints of endothelial apoptosis and/or necrosis. Whereas determination of tumor progression or treatment response can be established within the first year following treatment, the effects of radiation on normal tissue may take place over a number of years. Whether increases in $\mathrm{rCBV}$ and $\mathrm{rCBF}$ rations shown in our study are indicators of tissue sensitivity has yet to be determined and requires further study.

In conclusion lower $\mathrm{K}^{2}$ trans 1 week post-irradiation within the tumor margins is predictive of treatment response. Conversely lower rCBV at 1 month indicates progressive disease. $\mathrm{rCBV}$ and $\mathrm{rCBF}$ increases were seen from baseline to 1 week and 1 month outside of the tumor and occurring primarily in GM. Whether these measures are biomarkers of 
increased radiation damage and risk of necrosis cannot be determined. Further study is required to validate whether these biomarkers can serve as clinically useful surrogates to guide treatment decisions. 


\section{Bibliography}

Alemán-Gómez Y., Melie-García L., V.-H. P. (2006). IBASPM: Toolbox for automatic parcellation of brain structures. In 12th Annual Meeting of the Organization for Human Brain Mapping, Florence.

Arnold, S. M. and Patchell, R. A. (2001). Diagnosis and management of brain metastases. Hematology/oncology clinics of North America, 15(6):1085-107, vii.

Aronen, H. J., Gazit, I. E., Louis, D. N., Buchbinder, B. R., Pardo, F. S., Weisskoff, R. M., Harsh, G. R., Cosgrove, G. R., Halpern, E. F., and Hochberg, F. H. (1994). Cerebral blood volume maps of gliomas: comparison with tumor grade and histologic findings. Radiology, 191(1):41-51.

Barajas, R. F., Chang, J. S., Segal, M. R., Parsa, A. T., McDermott, M. W., Berger, M. S., and Cha, S. (2009). Differentiation of recurrent glioblastoma multiforme from radiation necrosis after external beam radiation therapy with dynamic susceptibility-weighted contrast-enhanced perfusion MR imaging. Radiology, 253(2):486-96.

Barnholtz-Sloan, J. S., Sloan, A. E., Davis, F. G., Vigneau, F. D., Lai, P., and Sawaya, R. E. (2004). Incidence proportions of brain metastases in patients diagnosed (1973 to 2001) in the Metropolitan Detroit Cancer Surveillance System. Journal of clinical oncology : official journal of the American Society of Clinical Oncology, 22(14):2865-72.

Berk, L. (1995). An overview of radiotherapy trials for the treatment of brain metastases. Oncology (Williston Park, N.Y.), 9(11):1205-12; discussion 1212-6, 1219.

Blouw, B., Haase, V. H., Song, H., Bergers, G., and Johnson, R. S. (2007). Loss of vascular endothelial growth factor expression reduces vascularization, but not growth, of tumors lacking the Von Hippel-Lindau tumor suppressor gene. Oncogene, 26(31):4531-40. 
Bulakbasi, N., Kocaoglu, M., Farzaliyev, A., Tayfun, C., Ucoz, T., and Somuncu, I. (2005). Assessment of diagnostic accuracy of perfusion MR imaging in primary and metastatic solitary malignant brain tumors. AJNR. American journal of neuroradiology, 26(9):2187-99.

Burnet, N. G., Johansen, J., Turesson, I., Nyman, J., and Peacock, J. H. (1998). Describing patients' normal tissue reactions: concerning the possibility of individualising radiotherapy dose prescriptions based on potential predictive assays of normal tissue radiosensitivity. Steering Committee of the BioMed2 European Union Concerted . International journal of cancer. Journal international du cancer, 79(6):606-13.

Burri, P. H., Hlushchuk, R., and Djonov, V. (2004). Intussusceptive angiogenesis: its emergence, its characteristics, and its significance. Developmental dynamics : an official publication of the American Association of Anatomists, 231(3):474-88.

Cairns, R. A., Kalliomaki, T., and Hill, R. P. (2001). Acute (cyclic) hypoxia enhances spontaneous metastasis of KHT murine tumors. Cancer research, 61(24):8903-8.

Cao, Y. (2011). The promise of dynamic contrast-enhanced imaging in radiation therapy. Seminars in radiation oncology, 21(2):147-56.

Cao, Y., Tsien, C. I., Nagesh, V., Junck, L., Ten Haken, R., Ross, B. D., Chenevert, T. L., and Lawrence, T. S. (2006). Survival prediction in high-grade gliomas by MRI perfusion before and during early stage of RT [corrected]. International journal of radiation oncology, biology, physics, 64(3):876-85.

Cao, Y., Tsien, C. I., Sundgren, P. C., Nagesh, V., Normolle, D., Buchtel, H., Junck, L., and Lawrence, T. S. (2009). Dynamic contrast-enhanced magnetic resonance imaging as a biomarker for prediction of radiation-induced neurocognitive dysfunction. Clinical cancer research : an official journal of the American Association for Cancer Research, 15(5):1747-54.

Casanovas, O., Hicklin, D. J., Bergers, G., and Hanahan, D. (2005). Drug resistance by evasion of antiangiogenic targeting of VEGF signaling in late-stage pancreatic islet tumors. Cancer cell, 8(4):299-309.

Cha, S. (2009). Neuroimaging in neuro-oncology. Neurotherapeutics, 6(3):465-77.

Cha, S., Johnson, G., Wadghiri, Y. Z., Jin, O., Babb, J., Zagzag, D., and Turnbull, D. H. (2003). Dynamic, contrast-enhanced perfusion MRI in mouse gliomas: correlation with histopathology. Magnetic resonance in medicine : official journal of 
the Society of Magnetic Resonance in Medicine / Society of Magnetic Resonance in Medicine, 49(5):848-855.

Cha, S., Knopp, E. a., Johnson, G., Litt, a., Glass, J., Gruber, M. L., Lu, S., and Zagzag, D. (2000). Dynamic contrast-enhanced T2-weighted MR imaging of recurrent malignant gliomas treated with thalidomide and carboplatin. AJNR. American journal of neuroradiology, 21(5):881-90.

Chang, E. L., Wefel, J. S., Hess, K. R., Allen, P. K., Lang, F. F., Kornguth, D. G., Arbuckle, R. B., Swint, J. M., Shiu, A. S., Maor, M. H., and Meyers, C. a. (2009). Neurocognition in patients with brain metastases treated with radiosurgery or radiosurgery plus whole-brain irradiation: a randomised controlled trial. The lancet oncology, 10(11):1037-44.

Chang, W. S., Kim, H. Y., Chang, J. W., Park, Y. G., and Chang, J. H. (2010). Analysis of radiosurgical results in patients with brain metastases according to the number of brain lesions: is stereotactic radiosurgery effective for multiple brain metastases? Journal of neurosurgery, 113 Suppl:73-8.

Chung, C., Jalali, S., Foltz, W., Burrell, K., Wildgoose, P., Lindsay, P., Graves, C., Camphausen, K., Milosevic, M., Jaffray, D., Zadeh, G., and Ménard, C. (2013). Imaging biomarker dynamics in an intracranial murine glioma study of radiation and antiangiogenic therapy. International journal of radiation oncology, biology, physics, 85(3):805-12.

Constine, L. S., Konski, A., Ekholm, S., McDonald, S., and Rubin, P. (1988). Adverse effects of brain irradiation correlated with $\mathrm{MR}$ and $\mathrm{CT}$ imaging. International journal of radiation oncology, biology, physics, 15(2):319-30.

Covarrubias, D. J., Rosen, B. R., and Lev, M. H. (2004). Dynamic magnetic resonance perfusion imaging of brain tumors. The oncologist, 9(5):528-37.

Deeken, J. F. and Löscher, W. (2007). The blood-brain barrier and cancer: transporters, treatment, and Trojan horses. Clinical cancer research : an official journal of the American Association for Cancer Research, 13(6):1663-74.

Delattre, J. Y., Krol, G., Thaler, H. T., and Posner, J. B. (1988). Distribution of brain metastases. Archives of neurology, 45(7):741-4.

Du, R., Lu, K. V., Petritsch, C., Liu, P., Ganss, R., Passegué, E., Song, H., Vandenberg, S., Johnson, R. S., Werb, Z., and Bergers, G. (2008). HIF1alpha induces the 
recruitment of bone marrow-derived vascular modulatory cells to regulate tumor angiogenesis and invasion. Cancer cell, 13(3):206-20.

Eichler, A. F., Chung, E., Kodack, D. P., Loeffler, J. S., Fukumura, D., and Jain, R. K. (2011). The biology of brain metastases-translation to new therapies. Nature reviews. Clinical oncology, 8(6):344-56.

Eichler, A. F. and Loeffler, J. S. (2007). Multidisciplinary management of brain metastases. The oncologist, 12(7):884-98.

El Kamar, F. G. and Posner, J. B. (2004). Brain metastases. Seminars in neurology, 24(4):347-62.

Essig, M. and Gerigk, L. (2009). Imaging of brain tumours and metastases. EJHP Practice, 15(6):30-32.

Essig, M., Waschkies, M., Wenz, F., Debus, J., Hentrich, H. R., and Knopp, M. V. (2003). Assessment of brain metastases with dynamic susceptibility-weighted contrast-enhanced MR imaging: initial results. Radiology, 228(1):193-9.

Fidler, I. J., Schackert, G., Zhang, R. D., Radinsky, R., and Fujimaki, T. (1999). The biology of melanoma brain metastasis. Cancer metastasis reviews, 18(3):387-400.

Folkman, J. and Camphausen, K. (2001). Cancer. What does radiotherapy do to endothelial cells? Science (New York, N.Y.), 293(5528):227-8.

Follwell, M. J., Khu, K. J., Cheng, L., Xu, W., Mikulis, D. J., Millar, B.-A., Tsao, M. N., Laperriere, N. J., Bernstein, M., and Sahgal, A. (2012). Volume specific response criteria for brain metastases following salvage stereotactic radiosurgery and associated predictors of response. Acta oncologica (Stockholm, Sweden), 51(5):62935 .

Fuss, M., Wenz, F., Scholdei, R., Essig, M., Debus, J., Knopp, M. V., and Wannenmacher, M. (2000). Radiation-induced regional cerebral blood volume (rCBV) changes in normal brain and low-grade astrocytomas: quantification and time and dose-dependent occurrence. International journal of radiation oncology, biology, physics, 48(1):53-8.

Gavrilovic, I. T. and Posner, J. B. (2005). Brain metastases: epidemiology and pathophysiology. Journal of neuro-oncology, 75(1):5-14.

Hlushchuk, R., Makanya, A. N., and Djonov, V. (2011). Escape mechanisms after antiangiogenic treatment, or why are the tumors growing again? The International 
journal of developmental biology, 55(4-5):563-7.

Hlushchuk, R., Riesterer, O., Baum, O., Wood, J., Gruber, G., Pruschy, M., and Djonov, V. (2008). Tumor recovery by angiogenic switch from sprouting to intussusceptive angiogenesis after treatment with PTK787/ZK222584 or ionizing radiation. The American journal of pathology, 173(4):1173-85.

Hoefnagels, F. W. a., Lagerwaard, F. J., Sanchez, E., Haasbeek, C. J. a., Knol, D. L., Slotman, B. J., and Vandertop, W. P. (2009). Radiological progression of cerebral metastases after radiosurgery: assessment of perfusion MRI for differentiating between necrosis and recurrence. Journal of neurology, 256(6):878-87.

Horton, J., Baxter, D. H., and Olson, K. B. (1971). The management of metastases to the brain by irradiation and corticosteroids. The American journal of roentgenology, radium therapy, and nuclear medicine, 111(2):334-6.

Hwang, T. L., Close, T. P., Grego, J. M., Brannon, W. L., Gonzales, F., Delattre, J. Y., Krol, G., Thaler, H. T., and Posner, J. B. (1996). Predilection of brain metastasis in gray and white matter junction and vascular border zones. Archives of neurology, $77(7): 741-4$.

Jackson, A., O'Connor, J., Thompson, G., and Mills, S. (2008). Magnetic resonance perfusion imaging in neuro-oncology. Cancer imaging: the official publication of the International Cancer Imaging Society, 8:186-99.

Jain, R. (2013). Measurements of tumor vascular leakiness using DCE in brain tumors: clinical applications. NMR in biomedicine, 26(8):1042-9.

Jain, R. K., di Tomaso, E., Duda, D. G., Loeffler, J. S., Sorensen, a. G., and Batchelor, T. T. (2007). Angiogenesis in brain tumours. Nature reviews. Neuroscience, $8(8): 610-22$.

Johnson, G., Wetzel, S. G., Cha, S., Babb, J., and Tofts, P. S. (2004). Measuring blood volume and vascular transfer constant from dynamic, $\mathrm{T}(2)^{*}$-weighted contrastenhanced MRI. Magnetic resonance in medicine: official journal of the Society of Magnetic Resonance in Medicine / Society of Magnetic Resonance in Medicine, 51(5):961-8.

Kang, T. W., Kim, S. T., Byun, H. S., Jeon, P., Kim, K., Kim, H., and Lee, J. I. (2009). Morphological and functional MRI, MRS, perfusion and diffusion changes after radiosurgery of brain metastasis. European journal of radiology, 72(3):370-80. 
Kargiotis, O., Geka, A., Rao, J. S., and Kyritsis, A. P. (2010). Effects of irradiation on tumor cell survival, invasion and angiogenesis. Journal of neuro-oncology, 100(3):323-38.

Kassner, A., Thornhill, R. E., Liu, F., Winter, P. M., Caruthers, S. D., Wickline, S. A., and Lanza, G. M. (2004). Assessment of angiogenesis : dynamic contrast-enhanced MRI with non-targeted ultraparamagnetic nanoparticles compared to Gd-DTPA in a rabbit vx2 tumor model. Contrast Media Mol Imaging, 5(3):5838-5838.

Khalsa, S. S. S., Chinn, M., Krucoff, M., and Sherman, J. H. (2013). The role of stereotactic radiosurgery for multiple brain metastases in stable systemic disease: a review of the literature. Acta neurochirurgica, 155(7):1321-7; discussion 1327-8.

Kocher, M., Soffietti, R., Abacioglu, U., Villà, S., Fauchon, F., Baumert, B. G., Fariselli, L., Tzuk-Shina, T., Kortmann, R.-D., Carrie, C., Ben Hassel, M., Kouri, M., Valeinis, E., van den Berge, D., Collette, S., Collette, L., and Mueller, R.-P. (2011). Adjuvant whole-brain radiotherapy versus observation after radiosurgery or surgical resection of one to three cerebral metastases: results of the EORTC 2295226001 study. Journal of clinical oncology : official journal of the American Society of Clinical Oncology, 29(2):134-41.

Kozin, S. V., Duda, D. G., Munn, L. L., and Jain, R. K. (2012). Neovascularization after irradiation: what is the source of newly formed vessels in recurring tumors? Journal of the National Cancer Institute, 104(12):899-905.

Kudo, K., Terae, S., Katoh, C., Oka, M., Shiga, T., Tamaki, N., and Miyasaka, K. (2003). Quantitative cerebral blood flow measurement with dynamic perfusion CT using the vascular-pixel elimination method: comparison with $\mathrm{H} 2(15) \mathrm{O}$ positron emission tomography. AJNR. American journal of neuroradiology, 24(3):419-26.

Kuonen, F., Secondini, C., and Rüegg, C. (2012). Molecular pathways: emerging pathways mediating growth, invasion, and metastasis of tumors progressing in an irradiated microenvironment. Clinical cancer research : an official journal of the American Association for Cancer Research, 18(19):5196-202.

Landis, S. H., Murray, T., Bolden, S., and Wingo, P. a. (1998). Cancer statistics, 1998. CA: a cancer journal for clinicians, 48(1):6-29.

Langley, R. R. and Fidler, I. J. (2011). The seed and soil hypothesis revisited-the role of tumor-stroma interactions in metastasis to different organs. International journal of cancer. Journal international du cancer, 128(11):2527-35. 
Langley, R. R. and Fidler, I. J. (2013). The biology of brain metastasis. Clinical chemistry, 59(1):180-9.

Larson, D., Flickinger, J., and Loeffler, J. (1993). The radiobiology of radiosurgery. International Journal of Radiation ..., (December):557-561.

Law, M., Cha, S., Knopp, E. a., Johnson, G., Arnett, J., and Litt, A. W. (2002). High-grade gliomas and solitary metastases: differentiation by using perfusion and proton spectroscopic MR imaging. Radiology, 222(3):715-21.

Law, M., Yang, S., Babb, J. S., Knopp, E. a., Golfinos, J. G., Zagzag, D., and Johnson, G. (2004). Comparison of cerebral blood volume and vascular permeability from dynamic susceptibility contrast-enhanced perfusion MR imaging with glioma grade. AJNR. American journal of neuroradiology, 25(5):746-55.

Law, M., Young, R., Babb, J., and Peccerelli, N. (2008). Gliomas: Predicting Time to Progression or Survival with Cerebral Blood Volume Measurements at Dynamic Susceptibility-weighted Contrast-enhanced Perfusion MR. ..., 247(2):490-8.

Leksell, L. (1983). Stereotactic radiosurgery. (April):797-803.

Linskey, M. E., Andrews, D. W., Asher, A. L., Burri, S. H., Kondziolka, D., Robinson, P. D., Ammirati, M., Cobbs, C. S., Gaspar, L. E., Loeffler, J. S., McDermott, M., Mehta, M. P., Mikkelsen, T., Olson, J. J., Paleologos, N. a., Patchell, R. a., Ryken, T. C., and Kalkanis, S. N. (2010). The role of stereotactic radiosurgery in the management of patients with newly diagnosed brain metastases: a systematic review and evidence-based clinical practice guideline. Journal of neuro-oncology, $96(1): 45-68$.

Ljubimova, N. V., Levitman, M. K., Plotnikova, E. D., and Eidus, L. K. (1991). Endothelial cell population dynamics in rat brain after local irradiation. The British journal of radiology, 64(766):934-40.

Loeffler, J. S., Barker, F. G., and Chapman, P. H. (1999). Role of radiosurgery in the management of central nervous system metastases. Cancer chemotherapy and pharmacology, 43 Suppl:S11-4.

Loeffler, J. S., Patchell, R., and Sawaya, R. E. (1997). Treatment of Metastatic Cancer. In Devita, V., Hellman, S., and Rosenberg, S., editors, Cancer: principles and practice of oncology, page 2523. Lippincott-Raven, Philadelphia, 5th edition.

Long, D. M. (1979). Capillary ultrastructure in human metastatic brain tumors. Journal of neurosurgery, 51(1):53-8. 
Lu, F., Li, Y.-Q., Aubert, I., and Wong, C. S. (2012). Endothelial cells regulate p53dependent apoptosis of neural progenitors after irradiation. Cell death 85 disease, 3:e324.

Lu-Emerson, C. and Eichler, A. F. (2012). Brain metastases. Continuum (Minneapolis, Minn.), 18(2):295-311.

Maitz, A. H. and Wu, A. (1998). Treatment planning of stereotactic convergent gammaray irradiation using Co-60 sources. Medical dosimetry : official journal of the American Association of Medical Dosimetrists, 23(3):169-75.

Markesbery, W. R., Brooks, W. H., Gupta, G. D., and Young, A. B. (1978). Treatment for patients with cerebral metastases. Archives of neurology, 35(11):754-6.

Milano, M. T., Usuki, K. Y., Walter, K. A., Clark, D., and Schell, M. C. (2011). Stereotactic radiosurgery and hypofractionated stereotactic radiotherapy: normal tissue dose constraints of the central nervous system. Cancer treatment reviews, 37(7):567-78.

Millar, B.-A. M., Purdie, T. G., Yeung, I., Pond, G. R., Billingsley, S., Wong, R., Haddad, P., Wong, C. S., and Laperriere, N. (2005). Assessing perfusion changes during whole brain irradiation for patients with cerebral metastases. Journal of neuro-oncology, 71(3):281-6.

Minniti, G., Clarke, E., Lanzetta, G., Osti, M. F., Trasimeni, G., Bozzao, A., Romano, A., and Enrici, R. M. (2011). Stereotactic radiosurgery for brain metastases: analysis of outcome and risk of brain radionecrosis. Radiation oncology (London, England), 6:48.

Monnier, Y., Farmer, P., Bieler, G., Imaizumi, N., Sengstag, T., Alghisi, G. C., Stehle, J.-C., Ciarloni, L., Andrejevic-Blant, S., Moeckli, R., Mirimanoff, R.-O., Goodman, S. L., Delorenzi, M., and Rüegg, C. (2008). CYR61 and alphaVbeta5 integrin cooperate to promote invasion and metastasis of tumors growing in preirradiated stroma. Cancer research, 68(18):7323-31.

Murphy, B. D., Fox, a. J., Lee, D. H., Sahlas, D. J., Black, S. E., Hogan, M. J., Coutts, S. B., Demchuk, a. M., Goyal, M., Aviv, R. I., Symons, S., Gulka, I. B., Beletsky, V., Pelz, D., Hachinski, V., Chan, R., and Lee, T.-Y. (2006). Identification of penumbra and infarct in acute ischemic stroke using computed tomography perfusion-derived blood flow and blood volume measurements. Stroke; a journal of cerebral circulation, 37(7):1771-7. 
Niranjan, A., Gobbel, G. T., Kondziolka, D., Flickinger, J. C., and Lunsford, L. D. (2004). Experimental radiobiological investigations into radiosurgery: present understanding and future directions. Neurosurgery, 55(3):495-504; discussion 504-5.

Nordal, R. A. and Wong, C. S. (2005). Molecular targets in radiation-induced blood-brain barrier disruption. International journal of radiation oncology, biology, physics, 62(1):279-87.

Oh, B. C., Pagnini, P. G., Wang, M. Y., Liu, C. Y., Kim, P. E., Yu, C., and Apuzzo, M. L. J. (2007). Stereotactic radiosurgery: adjacent tissue injury and response after high-dose single fraction radiation: Part I-Histology, imaging, and molecular events. Neurosurgery, 60(1):31-44; discussion 44-5.

Ostergaard, L., Hochberg, F. H., Rabinov, J. D., Sorensen, A. G., Lev, M., Kim, L., Weisskoff, R. M., Gonzalez, R. G., Gyldensted, C., and Rosen, B. R. (1999). Early changes measured by magnetic resonance imaging in cerebral blood flow, blood volume, and blood-brain barrier permeability following dexamethasone treatment in patients with brain tumors. Journal of neurosurgery, 90(2):300-5.

Pàez-Ribes, M., Allen, E., Hudock, J., Takeda, T., Okuyama, H., Viñals, F., Inoue, M., Bergers, G., Hanahan, D., and Casanovas, O. (2009). Antiangiogenic therapy elicits malignant progression of tumors to increased local invasion and distant metastasis. Cancer cell, 15(3):220-31.

Paget, S. (1989). The distribution of secondary growths in cancer of the breast. 1889. Cancer metastasis reviews, 8(2):98-101.

Patchell, R. A., Tibbs, P. A., Regine, W. F., Dempsey, R. J., Mohiuddin, M., Kryscio, R. J., Markesbery, W. R., Foon, K. A., and Young, B. (1998). Postoperative radiotherapy in the treatment of single metastases to the brain: a randomized trial. JAMA : the journal of the American Medical Association, 280(17):1485-9.

Peña, L. A., Fuks, Z., and Kolesnick, R. N. (2000). Radiation-induced apoptosis of endothelial cells in the murine central nervous system: protection by fibroblast growth factor and sphingomyelinase deficiency. Cancer research, 60(2):321-7.

Pennacchietti, S., Michieli, P., Galluzzo, M., Mazzone, M., Giordano, S., and Comoglio, P. M. (2003). Hypoxia promotes invasive growth by transcriptional activation of the met protooncogene. Cancer cell, 3(4):347-61.

Peterson, A. M., Meltzer, C. C., Evanson, E. J., Flickinger, J. C., and Kondziolka, D. (1999). MR imaging response of brain metastases after gamma knife stereotactic 
radiosurgery. Radiology, 211(3):807-14.

Posner, J. (1995). Neurologic complications of cancer. FA Davis, Philadelphia.

Posner, J. B. (1992). Management of brain metastases. Revue neurologique, 148(67):477-87.

Price, S. J., Jena, R., Green, H. a. L., Kirkby, N. F., Lynch, a. G., Coles, C. E., Pickard, J. D., Gillard, J. H., and Burnet, N. G. (2007). Early radiotherapy dose response and lack of hypersensitivity effect in normal brain tissue: a sequential dynamic susceptibility imaging study of cerebral perfusion. Clinical oncology (Royal College of Radiologists (Great Britain)), 19(8):577-87.

Price, S. J., Peña, A., Burnet, N. G., Jena, R., Green, H. a. L., Carpenter, T. A., Pickard, J. D., and Gillard, J. H. (2004). Tissue signature characterisation of diffusion tensor abnormalities in cerebral gliomas. European radiology, 14(10):1909-17.

Provenzale, J. M., Mukundan, S., and Barboriak, D. P. (2006). Diffusion-weighted and perfusion MR imaging for brain tumor characterization and assessment of treatment response. Radiology, 239(3):632-49.

Provenzale, J. M., Wang, G. R., Brenner, T., Petrella, J. R., and Sorensen, A. G. (2002). Comparison of permeability in high-grade and low-grade brain tumors using dynamic susceptibility contrast MR imaging. AJR. American journal of roentgenology, 178(3):711-6.

Roberts, H. C., Roberts, T. P., Bollen, a. W., Ley, S., Brasch, R. C., and Dillon, W. P. (2001). Correlation of microvascular permeability derived from dynamic contrastenhanced MR imaging with histologic grade and tumor labeling index: a study in human brain tumors. Academic radiology, 8(5):384-91.

Roberts, H. C., Roberts, T. P., Brasch, R. C., and Dillon, W. P. (2000). Quantitative measurement of microvascular permeability in human brain tumors achieved using dynamic contrast-enhanced MR imaging: correlation with histologic grade. AJNR. American journal of neuroradiology, 21(5):891-9.

Rofstad, E. K., Mathiesen, B., Henriksen, K., Kindem, K., and Galappathi, K. (2005). The tumor bed effect: increased metastatic dissemination from hypoxia-induced up-regulation of metastasis-promoting gene products. Cancer research, 65(6):238796.

Schell, M., Bova, F., Larson, D., and Leavitt, D. (1995). AAPM Report no. 54. .... Report of Task Group, (5). 
Schouten, L. J., Rutten, J., Huveneers, H. A. M., and Twijnstra, A. (2002). Incidence of brain metastases in a cohort of patients with carcinoma of the breast, colon, kidney, and lung and melanoma. Cancer, 94(10):2698-705.

Shaw, E., Scott, C., Souhami, L., Dinapoli, R., Kline, R., Loeffler, J., and Farnan, N. (2000). Single dose radiosurgical treatment of recurrent previously irradiated primary brain tumors and brain metastases: final report of RTOG protocol 90-05. International journal of radiation oncology, biology, physics, 47(2):291-8.

Soliman, H., Gunasekara, A., Rycroft, M., Zubovits, J., Dent, R., Spayne, J., Yaffe, M. J., and Czarnota, G. J. (2010). Functional imaging using diffuse optical spectroscopy of neoadjuvant chemotherapy response in women with locally advanced breast cancer. Clinical cancer research : an official journal of the American Association for Cancer Research, 16(9):2605-14.

Song, C., Park, H., and Griffin, R. (2012). Radiobiology of stereotactic radiosurgery and stereotactic body radiation therapy. In Basis of Radiation Therapy.

Sperduto, P. W., Chao, S. T., Sneed, P. K., Luo, X., Suh, J., Roberge, D., Bhatt, A., Jensen, A. W., Brown, P. D., Shih, H., Kirkpatrick, J., Schwer, A., Gaspar, L. E., Fiveash, J. B., Chiang, V., Knisely, J., Sperduto, C. M., and Mehta, M. (2010). Diagnosis-specific prognostic factors, indexes, and treatment outcomes for patients with newly diagnosed brain metastases: a multi-institutional analysis of 4,259 patients. International journal of radiation oncology, biology, physics, 77(3):655-61.

Stone, H., Coleman, C., Anscher, M., and McBride, W. (2003). Effects of radiation on normal tissue: consequences and mechanisms. The lancet oncology, pages 529-536.

Sun, A., Bae, K., Gore, E. M., Movsas, B., Wong, S. J., Meyers, C. a., Bonner, J. A., Schild, S. E., Gaspar, L. E., Bogart, J. a., Werner-Wasik, M., and Choy, H. (2011). Phase III trial of prophylactic cranial irradiation compared with observation in patients with locally advanced non-small-cell lung cancer: neurocognitive and quality-of-life analysis. Journal of clinical oncology : official journal of the American Society of Clinical Oncology, 29(3):279-86.

Taki, S., Higashi, K., Oguchi, M., Tamamura, H., Tsuji, S., Ohta, K., Tonami, H., Yamamoto, I., Okamoto, K., and Iizuka, H. (2002). Changes in regional cerebral blood flow in irradiated regions and normal brain after stereotactic radiosurgery. Annals of nuclear medicine, 16(4):273-7.

Therasse, P., Arbuck, S. G., Eisenhauer, E. A., Wanders, J., Kaplan, R. S., Rubinstein, 
L., Verweij, J., Van Glabbeke, M., van Oosterom, A. T., Christian, M. C., and Gwyther, S. G. (2000). New guidelines to evaluate the response to treatment in solid tumors. European Organization for Research and Treatment of Cancer, National Cancer Institute of the United States, National Cancer Institute of Canada. Journal of the National Cancer Institute, 92(3):205-16.

Tsai, J. H., Makonnen, S., Feldman, M., Sehgal, C. M., Maity, A., and Lee, W. M. F. (2005). Ionizing radiation inhibits tumor neovascularization by inducing ineffective angiogenesis. Cancer biology \& therapy, 4(12):1395-1400.

Tsao, M., Xu, W., and Sahgal, A. (2012). A meta-analysis evaluating stereotactic radiosurgery, whole-brain radiotherapy, or both for patients presenting with a limited number of brain metastases. Cancer, 118(9):2486-93.

Tsao, M. N., Laetsch, N. S., Wong, R. K. S., Laperriere, N., and Guidelines, C. (2004). A Quality Initiative of the Management of Brain Metastases : Role of Radiotherapy Alone or in Combination with Other Treatment Modalities.

Tsuruda, J. S., Kortman, K. E., Bradley, W. G., Wheeler, D. C., Van Dalsem, W., and Bradley, T. P. (1987). Radiation effects on cerebral white matter: MR evaluation. AJR. American journal of roentgenology, 149(1):165-71.

Vlad, R. M., Alajez, N. M., Giles, A., Kolios, M. C., and Czarnota, G. J. (2008). Quantitative ultrasound characterization of cancer radiotherapy effects in vitro. International journal of radiation oncology, biology, physics, 72(4):1236-43.

Weber, M.-A., Günther, M., Lichy, M. P., Delorme, S., Bongers, A., Thilmann, C., Essig, M., Zuna, I., Schad, L. R., Debus, J., and Schlemmer, H.-P. (2003). Comparison of arterial spin-labeling techniques and dynamic susceptibility-weighted contrastenhanced MRI in perfusion imaging of normal brain tissue. Investigative radiology, 38(11):712-8.

Weber, M. a., Zoubaa, S., Schlieter, M., Jüttler, E., Huttner, H. B., Geletneky, K., Ittrich, C., Lichy, M. P., Kroll, A., Debus, J., Giesel, F. L., Hartmann, M., and Essig, M. (2006). Diagnostic performance of spectroscopic and perfusion MRI for distinction of brain tumors. Neurology, 66(12):1899-906.

Wenz, F., Rempp, K., Hess, T., Debus, J., Brix, G., Engenhart, R., Knopp, M. V., van Kaick, G., and Wannenmacher, M. (1996). Effect of radiation on blood volume in low-grade astrocytomas and normal brain tissue: quantification with dynamic susceptibility contrast MR imaging. AJR. American journal of roentgenology, 
166(1):187-93.

Wood, K., Jawahar, A., Smelley, C., Mullapudi, S., DeLaune, A., Nanda, A., and Granger, D. N. (2005). Exposure of brain to high-dose, focused gamma rays irradiation produces increase in leukocytes-adhesion and pavementing in small intracerebral blood vessels. Neurosurgery, 57(6):1282-1288. 
